\title{
Suppression of Arctic Air Formation with Climate Warming: Investigation with a Two-Dimensional Cloud-Resolving Model ${ }^{\mathscr{O}}$
}

\author{
TIMOTHY W. CRONIN \\ Department of Earth, Atmospheric, and Planetary Sciences, Massachusetts Institute of Technology, \\ Cambridge, Massachusetts \\ HARRISON LI \\ Harvard University, Cambridge, Massachusetts \\ ELI TZIPERMAN \\ Department of Earth and Planetary Sciences, and School of Engineering and Applied Sciences, \\ Harvard University, Cambridge, Massachusetts
}

(Manuscript received 23 June 2016, in final form 2 June 2017)

\begin{abstract}
Arctic climate change in winter is tightly linked to changes in the strength of surface temperature inversions, which occur frequently in the present climate as Arctic air masses form during polar night. Recent work proposed that, in a warmer climate, increasing low-cloud optical thickness of maritime air advected over highlatitude landmasses during polar night could suppress the formation of Arctic air masses, amplifying winter warming over continents and sea ice. But this mechanism was based on single-column simulations that could not assess the role of fractional cloud cover change. This paper presents two-dimensional cloud-resolving model simulations that support the single-column model results: low-cloud optical thickness and duration increase strongly with initial air temperature, slowing the surface cooling rate as the climate is warmed. The cloud-resolving model cools less at the surface than the single-column model, and the sensitivity of its cooling to warmer initial temperatures is also higher, because it produces cloudier atmospheres with stronger lowertropospheric mixing and distributes cloud-top cooling over a deeper atmospheric layer with larger heat capacity. Resolving larger-scale cloud turbulence has the greatest impact on the microphysics schemes that best represent general observed features of mixed-phase clouds, increasing their sensitivity to climate warming. These findings support the hypothesis that increasing insulation of the high-latitude land surface by low clouds in a warmer world could act as a strong positive feedback in future climate change and suggest studying Arctic air formation in a three-dimensional climate model.
\end{abstract}

\section{Introduction}

In recent decades, the Arctic has warmed faster than the rest of the globe, particularly during winter (Chylek et al. 2009; Hartmann et al. 2013), and Arctic-amplified warming is expected to continue through the twenty-first century according to climate model simulations (Holland and Bitz 2003; Pithan and Mauritsen 2014).

Supplemental information related to this paper is available at the Journals Online website: http://dx.doi.org/10.1175/JAS-D-160193.s1.

Corresponding author: Timothy W. Cronin, twcronin@mit.edu
Arctic amplification of temperature change occurs in models primarily because of positive feedbacks that act at high latitudes, especially those related to decreased surface albedo from melting of ice and snow, and to changes in the tropospheric lapse rate (Pithan and Mauritsen 2014), though it can also occur without locally amplifying feedbacks because of increased poleward atmospheric heat transport (e.g., Alexeev and Jackson 2013). Although changes in tropospheric lapse rate contribute strongly to Arctic amplification, assessment of lapse-rate changes in models has often been diagnostic; a more process-based understanding of the controls on high-latitude lapse rates and surface inversion strength is needed. 
Recent work by Cronin and Tziperman (2015) found amplified surface warming and weaker surface inversions over high-latitude winter continents due to increasing insulation of the surface by optically thick liquid clouds in a single-column model. The goal of this study is to test the viability and strength of this mechanism-increased surface insulation by low clouds in a warmer world-in a model that resolves cloud dynamics at scales of $\sim 100 \mathrm{~m}-10 \mathrm{~km}$ and to compare cloud-resolving and single-column model results.

Arctic air formation is an initial-value problem in which an air mass with a prescribed initial temperature and moisture profile is allowed to cool by radiation to space over a low-heat-capacity surface in the absence of sunlight. This idealized problem represents the advection of maritime air over high-latitude land or sea ice during polar night. The concept of Arctic air formation was first introduced by Wexler (1936), who explored the transformation of polar maritime air into Arctic air by longwave radiative cooling in the absence of sunlight or clouds. Based on observed soundings during events of high-latitude airmass stagnation over land, Wexler (1936) suggested that the temperature profile of an Arctic air mass could be represented by a relatively cold isothermal layer overlying an even colder surface inversion layer. Both the isothermal layer and the inversion layer cool as time progresses and the isothermal layer deepens; in essence, radiative cooling of the surface to space steadily consumes the heat content of the lower troposphere from beneath.

Work since the study of Wexler (1936) has slowly built from his original idea. Curry (1983) used a one-dimensional model with more detailed radiative transfer to examine the role of clouds, subsidence, and turbulence on the formation of Arctic air and found that the process is especially sensitive to the amount of condensate in the atmosphere and its partitioning between liquid and ice. Overland and Guest (1991) conducted longer simulations, including a modification of the problem to explore equilibrium Arctic atmospheric temperature structure in winter. They also examined the rapid adjustment of surface temperature and inversion strength to transitions between clear and cloudy skies. Emanuel (2008) performed single-column model calculations of Arctic airmass formation and showed that, owing to its large static stability, Arctic air has greater saturation potential vorticity relative to the rest of the troposphere, which may allow it to play an important role in development of midlatitude weather systems.

Arctic air formation has also been linked to the broader investigation of Arctic mixed-phase clouds and boundary layer dynamics, airmass transformation, and the role of the surface energy balance throughout the year in sea ice loss. The longwave radiative effect of clouds is a large term in the Arctic surface energy balance in all seasons and consequently regulates ice loss over both land and sea, with more ice loss typical under cloudy conditions despite less absorption of shortwave radiation (Kapsch et al. 2013; Van Tricht et al. 2016; Mortin et al. 2016). From a Lagrangian standpoint, clouds form as warm and moist air masses are advected and cooled over the Arctic Ocean in both summer, leading to ice melt and fog (Tjernstrom et al. 2015), and winter, leading to bottom-heavy warming and weakening of surface inversions (Woods and Caballero 2016). A key finding from recent field studies in the Arctic is bimodality of the Arctic winter boundary layer: the coupled system of boundary layer and surface prefer to reside in either a "radiatively clear" state or an "opaquely cloudy" state (Stramler et al. 2011; Morrison et al. 2012). The radiatively clear state is characterized by clear skies or optically thin ice cloud, a colder surface and stronger surface inversion, and net surface radiative cooling of $\sim 40 \mathrm{~W} \mathrm{~m}^{-2}$, whereas the opaquely cloudy state is characterized by presence of cloud liquid, a warmer surface under a weaker elevated inversion, and near-zero surface net radiation. Pithan et al. (2014) found that similar distinct clear and cloudy states emerge in a single-column simulation of Arctic air formation and that a bimodal distribution of surface longwave radiation emerges when the transient cooling process is sampled in time. They also found that many climate models fail to capture this bimodality because of insufficient maintenance of supercooled cloud liquid and thus a poor representation of Arctic mixed-phase clouds. Pithan et al. (2016) followed on this work and used an intercomparison of Arctic air formation in single-column versions of several weather and climate models to understand the strengths and biases in model representation of both the clear and cloudy boundary layer states.

Cronin and Tziperman (2015) focused on the climate sensitivity of the process of Arctic air formation, by modifying the temperature of the initial sounding (representing maritime air) while holding relative humidity fixed. They found that a warmer initial atmosphere leads to longer-lasting low clouds and a reduced surface cooling rate, suppressing Arctic air formation and potentially amplifying winter continental warming, which would help explain continental warmth in past climates (e.g., Greenwood and Wing 1995). Increasing optical thickness of low clouds with warming results from both increasing condensate amount and from the change in cloud phase from ice to liquid. From the perspective of boundary layer states, a warmer initial atmosphere increases the fraction of the cooling period spent in the opaquely cloudy state. 
One potential concern that could be raised with these findings, however, is that the single-column model used in Cronin and Tziperman (2015) did not allow for fractional cloud cover. A decrease in cloud fraction with warming would damp the effect of more cloud condensate on reducing the surface cooling rate. Furthermore, all single-column models rely on parameterizations to represent processes of convection, cloud-top mixing, and entrainment, which are important in Arctic mixedphase clouds and may change with warming (e.g., Morrison et al. 2012). It is not trivial that a twodimensional model, which explicitly resolves these processes down to a scale of a few hundred meters (although parameterizations are still used for mixing at smaller scales), would have the same sensitivity to warming as a single-column model.

To test the suppression of Arctic air formation with climate warming found by Cronin and Tziperman (2015), this paper studies the process of Arctic air formation and its sensitivity to temperature in a twodimensional cloud-resolving model. We find that clouds tend to have large fractional area coverage and that increased mixing and deeper cloud layers actually lead to more cloud cover and less surface cooling in the two-dimensional model than in the single-column model. Thus, sensitivity of the two-dimensional model is broadly consistent with Cronin and Tziperman (2015): warming of the initial atmosphere leads to more low clouds and a reduced surface cooling rate. The twodimensional model, however, is even more sensitive than the single-column model to warming of the initial atmosphere, especially for the microphysics schemes with the best representation of general observed features found in mixed-phase clouds. We describe the model setup in section 2, present results in section 3, and discuss our findings in section 4 .

\section{Model description}

We use a two-dimensional idealized configuration of the Weather Research and Forecasting (WRF, version 3.4.1) Model to simulate the process of Arctic air formation over a low-heat-capacity land surface for a 14-day period during polar night. Simulations span a range of different initial temperature profiles and microphysics schemes. Many aspects of the model setup follow Cronin and Tziperman (2015), and these are summarized below. The surface is a uniform moist slab with the roughness of an ocean surface and heat capacity $C_{S}=2.1 \times 10^{5} \mathrm{~J} \mathrm{~m}^{-2} \mathrm{~K}^{-1}$. This heat capacity is equivalent to a water layer of depth of $5 \mathrm{~cm}$ and corresponds to the heat capacity of the surface layer of a deep snowpack that communicates with the atmosphere on a 1-day time scale. Roughness lengths in the main set of simulations are $\sim 1-4 \times 10^{-5} \mathrm{~m}$; sensitivity tests with larger roughness lengths of $10^{-4}$ and $10^{-3} \mathrm{~m}$ differ little in a qualitative sense but have slightly colder $2-\mathrm{m}$ air temperatures because the cold surface is more strongly coupled to the atmosphere. Initial temperature profiles are defined by a single parameter, the initial 2-m air temperature $T_{2}(0)$ (note that we use the terms " $2-\mathrm{m}$ air temperature" and "surface air temperature" interchangeably in this paper). Above the surface, initial soundings have a tropospheric lapse rate that is either moist adiabatic or $-8 \mathrm{~K} \mathrm{~km}^{-1}$, whichever is more stable, and an isothermal stratosphere at $-60^{\circ} \mathrm{C}$. The initial relative humidity profile decreases from $80 \%$ at the surface to $20 \%$ at $600 \mathrm{hPa}$; above $600 \mathrm{hPa}$ the relative humidity is constant at $20 \%$ up to the tropopause and set to a mixing ratio of $0.003 \mathrm{~g} \mathrm{~kg}^{-1}$ in the stratosphere. These temperature and humidity profiles are chosen to mimic those in Pithan et al. (2014) and Pithan et al. (2016), but with moist adiabatic stratification allowing for extension to warmer initial profiles without leading to moist convective instability. In this paper, we use the phrase "climate warming" synonymously with "warming of the initial atmospheric state."

The model domain is $15 \mathrm{~km}$ long, $\sim 15 \mathrm{~km}$ high, and periodic in the horizontal, with a horizontal grid spacing of $100 \mathrm{~m}$ and a uniform initial vertical grid spacing of $50 \mathrm{~m}$. Cronin and Tziperman (2015) used a stretched grid, with spacing increasing from $\sim 20 \mathrm{~m}$ at the surface to $\sim 200 \mathrm{~m}$ at $2-\mathrm{km}$ altitude and becoming even coarser higher up, so this study represents all clouds that are not fog with more vertical detail. The model time step for dynamics is $1.5 \mathrm{~s}$, the Coriolis parameter is set to zero, and no cumulus parameterization scheme is used. The spacing of levels in height decreases with time in each simulation because the vertical coordinate in the model is based on hydrostatic pressure, so cooling causes compression (by roughly $20 \%$ for $55^{\circ} \mathrm{C}$ of cooling at a starting temperature of $\left.0^{\circ} \mathrm{C}\right)$. Although the simulations in Cronin and Tziperman (2015) extend to 35-km height, we reduce the vertical extent of the model here because the stratosphere is not essential for this problem. We also run the model with varied grid spacing in both the horizontal and vertical to test the robustness of the main results (see section $4 \mathrm{~d}$ ). To stimulate turbulent mixing near the surface (both parameterized mixing and resolved eddies) and prevent the development of stationary surface temperature heterogeneities, a uniform initial $5 \mathrm{~m} \mathrm{~s}^{-1}$ zonal wind is imposed everywhere, and the horizontal-mean flow is relaxed to this value over a 1-day period. To allow development of horizontal asymmetries, we initialize the lowest four levels in the model with random temperature perturbations that are 
spatially white and chosen from a uniform distribution between -0.1 and $+0.1 \mathrm{~K}$.

Longwave radiative transfer in the model is parameterized using the Rapid Radiative Transfer Model for GCMs (RRTMG) scheme (Iacono et al. 2008), which is called every $2 \mathrm{~min}$. Sensitivity tests with $6 \mathrm{~s}$ between radiation calls lead to minimal difference in the results but are substantially more computationally costly. Shortwave radiation is zero at all times, because the latitude is set to $90^{\circ} \mathrm{N}$, and the model runs occur during the first 2 weeks of January. We use the Yonsei University (YSU) boundary layer scheme, which diffuses heat and moisture nonlocally within a layer of depth diagnosed using a bulk Richardson number (Hong et al. 2006). Because the near-surface stability in our model setup is often very high, and winds are relatively weak, diagnosed boundary layer depths are small: rarely up to a few hundred meters and often less than $50 \mathrm{~m}$ in depth. Resolved turbulent flow dominates transport above this height. Surface turbulent fluxes are parameterized using Monin-Obukhov similarity with separate lookup functions for different stability classes, and the latent heat flux is not allowed to be negative (i.e., there is no dew or frost). Test simulations allowing for dew and frost show small effects on the surface energy balance and do not substantially alter our findings.

One advantage of using WRF is the ability to easily test different parameterizations of cloud microphysics. The six schemes are denoted Lin-Purdue, WRF singlemoment 6-class (WSM6), Goddard, Thompson, Morrison, and Stony Brook, and some basic information on each is given in the appendix, with a focus on generation processes for cloud ice. Microphysics schemes are called at every model time step. As in Cronin and Tziperman (2015), some results are shown only for the Lin-Purdue microphysics scheme, but many plots show the mean and spread of the six microphysics schemes used. The Lin-Purdue scheme is a relatively simple bulk (single moment) scheme that models six hydrometeors-water vapor, cloud liquid, cloud ice, snow, rain, and graupelassuming exponential size distributions of rain, snow, and graupel particles (Lin et al. 1983). We also perform sensitivity tests labeled "no-CRF," where cloudradiation interactions are disabled; the Lin-Purdue scheme is still used, but cloud water concentrations are set to zero in the radiative transfer scheme (latent heat associated with phase changes is still considered). Comparing no-CRF results to the results with radiatively active clouds allows us to quantify the impact of cloud longwave forcing on Arctic air formation.

To explore the effects of surface heterogeneity, we also perform a set of sensitivity tests with the LinPurdue scheme, where the surface heat capacity is heterogeneous but has the same domain-average value. We set $C_{S}=9.66 \times 10^{5} \mathrm{~J} \mathrm{~m}^{-2} \mathrm{~K}^{-1}(23 \mathrm{~cm}$ of water equivalent) in a contiguous $10 \%$ of the domain and $C_{S}=$ $1.26 \times 10^{5} \mathrm{~J} \mathrm{~m}^{-2} \mathrm{~K}^{-1}(3 \mathrm{~cm}$ of water equivalent) elsewhere. This heterogeneity in surface heat capacity is intended as a crude representation of leads in sea ice, or areas of shallow water over land (i.e., lakes, wetlands, and streams). Although the true heat capacity of such heterogeneities in land cover would likely be larger, we do not want to complicate the interpretation of these sensitivity tests by also modifying the domain-average surface heat capacity. Limitations in our treatment of the surface are further discussed in section $4 \mathrm{~d}$.

One important caveat of this modeling setup is that, although some of the microphysics schemes predict particle sizes in different categories, this information is not passed to the RRTMG radiation scheme. Rather, in the version of WRF that we use, only the total cloud liquid and ice content in each column and vertical level is passed to RRTMG, and the radiation scheme makes assumptions about the cloud particle sizes. With more complete radiation-microphysics coupling, differences in microphysics schemes would likely affect the results more than indicated here.

\section{Results}

\section{a. Time evolution of temperature and clouds}

An increase in cloudiness with warmer initial states is evident from snapshots of modeled Arctic air formation after 4 days of cooling from initial 2-m air temperatures $T_{2}(0)$ of $0^{\circ}, 10^{\circ}$, and $20^{\circ} \mathrm{C}$ and the Lin-Purdue microphysics scheme (Fig. 1). Video S1 in the supplemental material also shows the evolution of the cloud fields and temperature profiles over the whole 2-week period; below, we summarize this evolution over the first 4 days to explain the origins of different cloud structures in Fig. 1. Analogous supplemental videos S2-S6 are included to show simulations with the other microphysics schemes but are not discussed in detail.

When the initial surface temperature is $T_{2}(0)=0^{\circ} \mathrm{C}$ (Fig. 1a), a physically thin but optically thick mixedphase fog forms after about $6 \mathrm{~h}$ of initial clear-sky cooling but dissipates in roughly a day as a result of scavenging of cloud water by snow, leaving behind tenuous ice clouds and snow. Although the surface temperature rebounds slightly when fog forms, the first 4 days are dominated by clear-sky surface cooling by more than $25^{\circ} \mathrm{C}$ and development of a strong surface inversion. With a warmer initial surface temperature of $T_{2}(0)=10^{\circ} \mathrm{C}$ (Fig. 1b), a surface fog layer again forms after about $6 \mathrm{~h}$, but it is all liquid and deepens rapidly. An elevated stratus layer detaches from the surface fog 


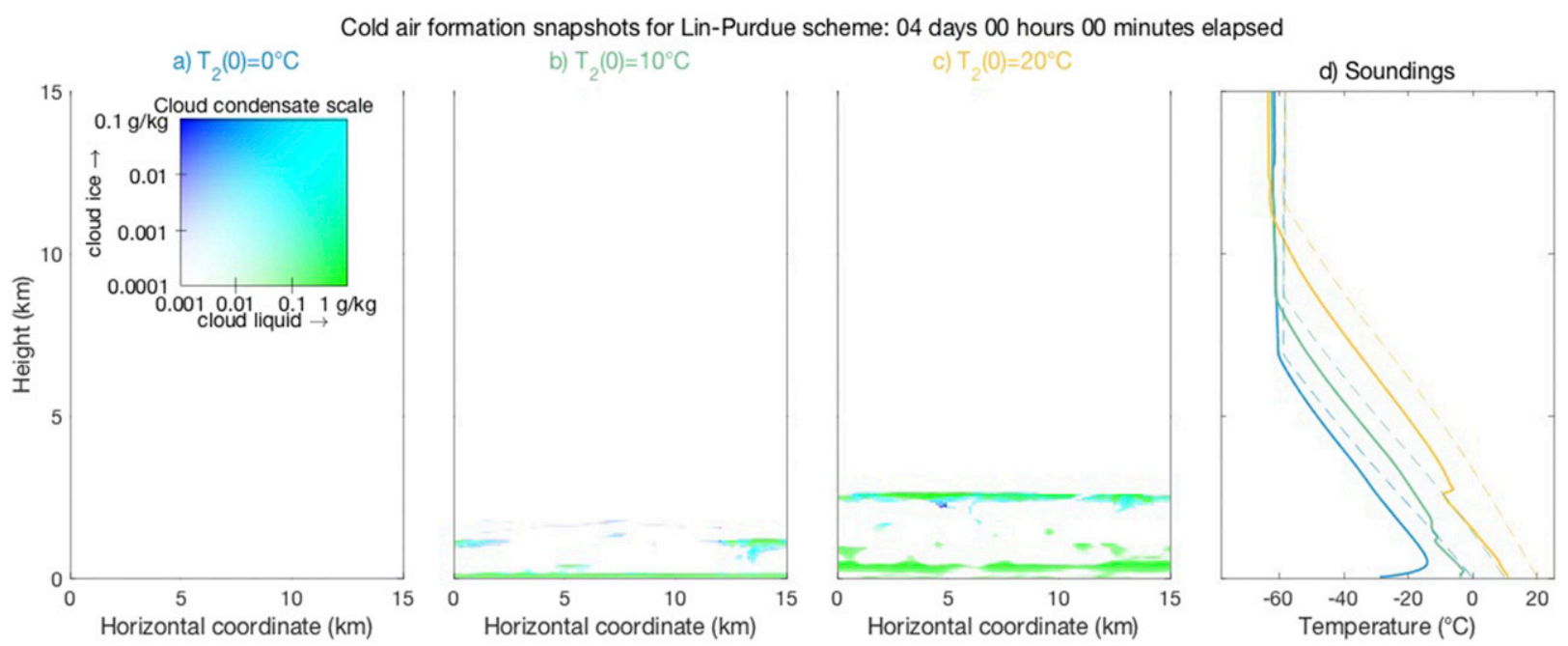

FIG. 1. Snapshots at day 4 of clouds as a function of height and $x$ coordinate for simulations with initial 2-m temperatures of (a) $0^{\circ}$, (b) $10^{\circ}$, and (c) $20^{\circ} \mathrm{C}$. Cloud liquid and cloud ice content are plotted with a two-dimensional logarithmic scale inset in (a): light to dark blues indicate cloud ice from 0.001 to $0.1 \mathrm{~g} \mathrm{~kg}^{-1}$, light to dark greens indicate cloud liquid from 0.01 to $1 \mathrm{~g} \mathrm{~kg}^{-1}$, and shades of cyan indicate mixed-phase clouds containing both liquid and ice. (d) Domain-average temperature profiles show development of a strong surface-based inversion in the cold simulation and deeper but less-cold convective surface layers beneath cloud-top inversions for the warmer simulations. Video S1 shows time evolution of this figure over the full 14 days of the three simulations.

around hour 36, grows upward into the clear background air, develops some ice after about hour 48 as it continues to cool, and then dissipates rapidly by precipitation just before the end of day 3. A new cloud layer beneath, limited in its growth by effects of the overlying cloud layer (weakened radiative cooling and precipitation), then rapidly thickens and deepens and repeats the cycle of growth and decay over day 4 . At the end of day 4, the broken remnants of this second mixed-phase stratus cloud layer lie at about $1.5-\mathrm{km}$ altitude, and a new liquid fog layer is beginning to form at the surface. As a consequence of strong longwave cloud radiative forcing during this sequence of two cloud-layer life cycles, the surface has cooled only by about $12^{\circ} \mathrm{C}$ by the end of the fourth day, and there is only a very weak surface inversion. For an even warmer initial surface temperature of $T_{2}(0)=20^{\circ} \mathrm{C}$ (Fig. 1c), the initial evolution and growth of the surface fog layer is very similar to the $T_{2}(0)=10^{\circ} \mathrm{C}$ case. The stratus layer at $\sim 2.5 \mathrm{~km}$, however, has persisted continuously since it detached from the initial fog layer around hour 32 and is only just beginning to develop ice and dissipate in the snapshot shown in Fig. 1c. There is also a second optically thick liquid cloud layer below it. This abundant and persistent cloud cover displaces radiative cooling upward from the surface to the top of the upper cloud layer, resulting in only $\sim 10^{\circ} \mathrm{C}$ of surface cooling by the end of the fourth day, with the low-level lapse rate remaining nearly moist adiabatic as in the initial state. At the end of day 4, the region between the two cloud layers for $T_{2}(0)=20^{\circ} \mathrm{C}$ is convective (see video S1), with horizontal fluctuations of vertical velocity $\sim 0.2 \mathrm{~m} \mathrm{~s}^{-1}$.

The behavior and structure of mixed-phase clouds in the warm and very warm simulations $\left[T_{2}(0)=10^{\circ}\right.$ and $20^{\circ} \mathrm{C}$, respectively] in Fig. 1 bear some resemblance to real Arctic mixed-phase clouds. Supercooled liquid overlies ice, ice and snow fall gradually, updrafts and entrainment through a moist inversion supply new cloud water, and multiple cloud layers form in areas of both stable and moist adiabatic stratification (e.g., Morrison et al. 2012; Sedlar et al. 2011; Verlinde et al. 2013). The most serious deficiencies of the simulations with the Lin-Purdue scheme are that new clouds are too commonly mixtures of ice and liquid because of the implementation of supersaturation adjustment (see the appendix) and that the scheme does not maintain enough supercooled liquid at low temperatures. Inspection of the WRF implementation of the Lin-Purdue scheme reveals that it cannot form any new supercooled liquid by condensation below $-25^{\circ} \mathrm{C}$ and thus cannot simulate persistent mixed-phase clouds when the cloud layer cools below $-10^{\circ} \mathrm{C}$, instead switching rapidly into the radiatively clear boundary layer state. Other schemes generally share this deficiency of maintaining too little supercooled liquid-or, equivalently, a toohigh glaciation temperature (see the appendix)—similar to findings by Pithan et al. (2014) for global models. In broad terms, the WSM6 (video S2) and Goddard (video S3) schemes do a poorer job than the Lin-Purdue scheme of representing mixed-phase clouds; they both 
lack the basic supercooled liquid-over-ice morphology. WSM6 simulates much more cloud ice than any other scheme and has a glaciation temperature only slightly below $0^{\circ} \mathrm{C}$. The Thompson (video S4) and Morrison (video S5) schemes represent mixed-phase clouds better than the Lin-Purdue scheme: both are able to maintain a mixed-phase cloud layer that grows upward and persists for 2-3 days in the $T_{2}(0)=0^{\circ} \mathrm{C}$ case. Morrison and Pinto (2005), one of the primary papers documenting the Morrison scheme, applied it in WRF to a case study of Arctic mixed-phase stratus and found that the scheme was able to capture key qualitative features of the clouds, as well as quantitative features such as cloud droplet number concentration and cloud water path. The Stony Brook (video S6) scheme has nearly identical cloud ice and cloud liquid physics to the Lin scheme and thus has similar strengths and weaknesses in depicting Arctic mixed-phase clouds.

Snapshots of domain-average soundings and cloud properties every 2 days during the cooling process also show the strong increase in cloudiness with warming of the initial state for the Lin-Purdue microphysics scheme (Fig. 2). Whenever low-level liquid clouds are present, they prevent the development of the surface inversion characteristic of Arctic air, instead giving rise to a strong cloud-top inversion with temperatures increasing from the cloud top down to the surface (Fig. 2). Consequently, the simulation with $T_{2}(0)=20^{\circ} \mathrm{C}$ has a total surface air temperature decrease of $39.7^{\circ} \mathrm{C}$ over 2 weeks, compared to $52.2^{\circ} \mathrm{C}$ for $T_{2}(0)=10^{\circ} \mathrm{C}$ and $57.3^{\circ} \mathrm{C}$ for $T_{2}(0)=0^{\circ} \mathrm{C}$. Comparing the evolution of surface longwave fluxes (Fig. 3a) with the soundings in Fig. 2 shows the correspondence between suppressed surface cooling rates and the presence of low-level liquid clouds. Figure 3c explicitly shows that warmer initial states have a more positive and more persistent surface cloud longwave forcing; for the warmest case, surface cloud longwave forcing increases until after day 10. Turbulent surface heat fluxes also regulate the total cooling rate under clear skies; once the cloud layer dissipates in each simulation, about half of the surface radiative cooling is offset by sensible heating of the surface (by warmer overlying air in the surface inversion; negative fluxes indicate warming of the surface in Fig. 3b).

Synchronous spikes in surface longwave cooling (upward) and surface cloud radiative effect and condensate path (downward) appear prominently for the warmest simulation in Fig. 3. These spikes occur as a result of quasi-periodic formation and upward propagation of a near-surface fog and stratus cloud layer, which repeatedly transforms into cumulus convection and dissipates, allowing the surface to cool and again form a fog layer (see video S1; frames near and leading up to a spike at day 4 , hour 21 provide a good example). The frequency of these spikes is $\sim 1-2$ day $^{-1}$, but the timing, regularity, and amplitude varies substantially across microphysics schemes (see videos S2-S6). Although these spikes are an intriguing feature of the warmer simulations, they do not seem to play a key role in any of the main conclusions, and, consequently, we do not discuss them further.

Simulations with heterogeneous surface heat capacity share many of these features, with similar time series of surface energy balance, cloud radiative forcing, vertically integrated cloud condensate, and even similar timing of spikes in the warmest simulation (dashed-dotted lines in Fig. 3). An additional result from these simulations is that thick clouds not only suppress surface cooling, they also reduce the spatial variability in surface air temperature (Fig. 3e). In clear-sky conditions, the surface cools less quickly where it has high heat capacity, and more quickly elsewhere. This differential surface cooling rate leads to 2 -m air temperatures that vary spatially by $\sim 4^{\circ} \mathrm{C}$ in the clear state, but only $\sim 0.5^{\circ} \mathrm{C}$ in the cloudy state. Increased duration of optically thick clouds in a warmer initial atmosphere thus allows not only for maintenance of warmer conditions overall, but also for better redistribution of heat within the domain, from locally warm areas to locally cold ones. A speculative consequence of this finding would be that inland water bodies-even if they are relatively shallow-could play more of a role in moderating continental temperatures in warmer climates because their heat could be redistributed nonlocally by advection in a deeper cloud-topped boundary layer, rather than being lost locally by radiation to space.

Surface air temperature evolution across the six microphysics schemes shows that warming the initial atmosphere leads to a strong reduction in the surface cooling rate over the 2 -week cooling period, especially over the first week (Fig. 4a). Time series of the surface air cooling $\left[T_{2}(0)-T_{2}(t)\right]$ averaged across microphysics schemes show a brief initial clear-sky cooling period (lasting well under a day), followed by progressively longer plateaus in surface air temperature for warmer initial states (Fig. 4b). The no-CRF simulations show that surface air cooling would be much less sensitive to the initial atmospheric temperature under radiatively clear skies (dashed-dotted lines in Fig. 4b).

Time series of cloud fraction (Fig. 5) aid in understanding the large spread in 2-m temperature across microphysics schemes shown in Fig. 4a. We define the cloud fraction as the fraction of grid cells with cloud condensate path-both liquid and ice-greater than $20 \mathrm{~g} \mathrm{~m}^{-2}$. Our conclusions are not strongly sensitive to this choice of threshold of $20 \mathrm{~g} \mathrm{~m}^{-2}$, which is based on a combination of observations and modeling (Morrison 

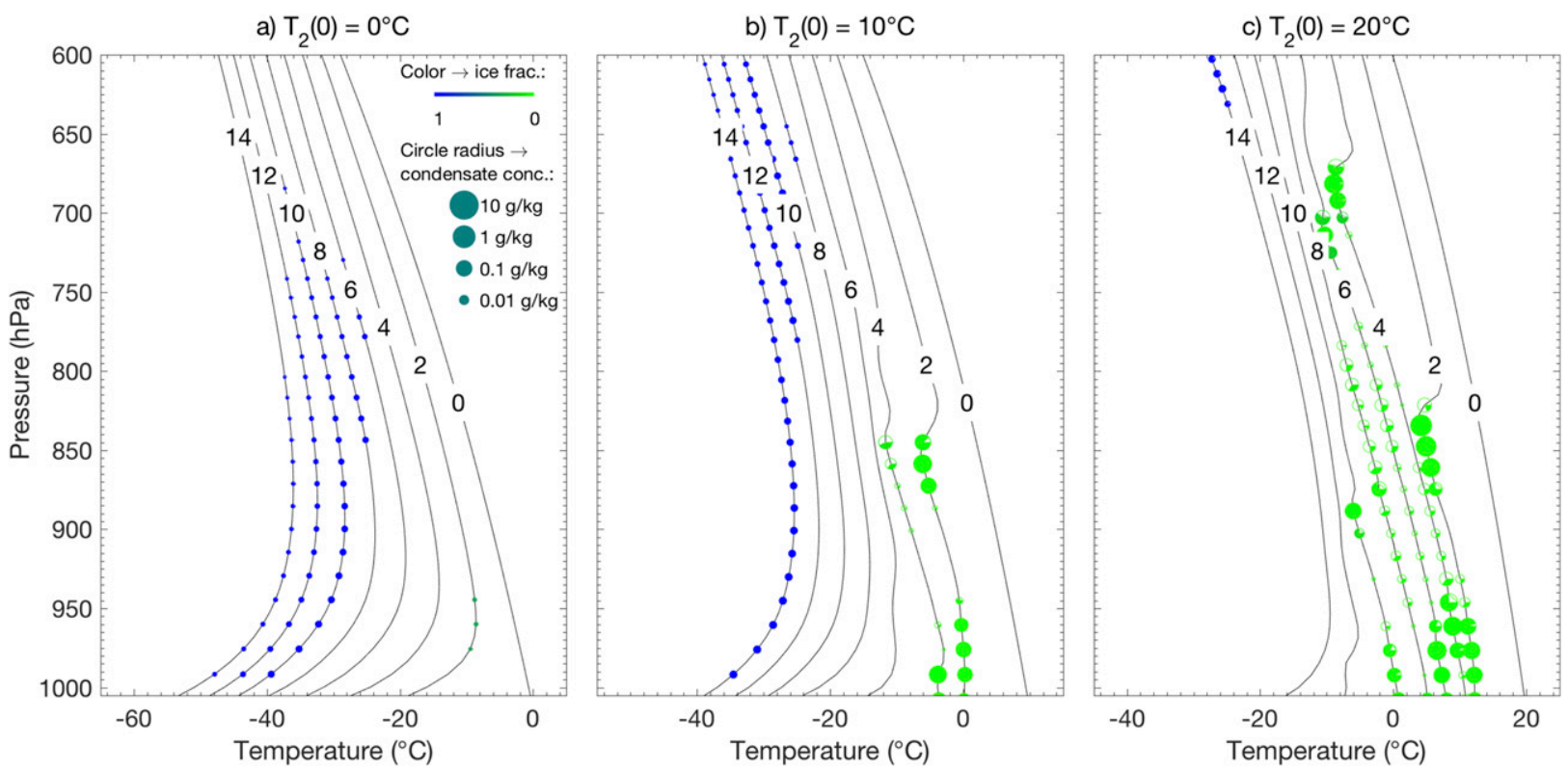

FIG. 2. Lower-tropospheric temperature profiles as a function of pressure at 2-day intervals (black lines) for simulations using the LinPurdue microphysics scheme. Subplots are for initial 2-m temperatures of (a) $0^{\circ}$, (b) $10^{\circ}$, and (c) $20^{\circ} \mathrm{C}$. Colored circles display information about the clouds at every other vertical level: circle radius is proportional to the logarithm of total cloud condensate, circle color indicates ice fraction in a linear scale from green (all liquid) to blue (all ice), and the fractional fill of a circle at a given level corresponds to the cloud fraction at that level. Grid cells are considered cloud if condensed water exceeds $0.001 \mathrm{~g} \mathrm{~kg}^{-1}$, so small filled blue dots in (a) and (b) indicate very optically thin ice clouds that cover the full domain.

and Pinto 2005), use in previous work on cloud fraction at high latitudes (Zuidema and Joyce 2008), physical reasoning that liquid clouds with droplets of effective radius $10 \mu \mathrm{m}$ have optical thickness $\sim 1$ for condensate paths $\sim 10 \mathrm{~g} \mathrm{~m}^{-2}$, and the empirical result that this threshold is large enough to exclude most of our simulated higher-altitude ice clouds but small enough to include most of our lower-altitude mixed-phase stratus. Most microphysics schemes show a rapid transition from the opaquely cloudy to the radiatively clear state as time passes (Fig. 5; also visible in Figs. 3c,d). The greatest spread in surface air temperature across microphysics schemes occurs when some microphysics schemes still have optically thick cloud layers but others do not, and this time window occurs progressively later for warmer initial atmospheres: around days $1-4$ for $T_{2}(0)=0^{\circ} \mathrm{C}$, days $4-10$ for $T_{2}(0)=10^{\circ} \mathrm{C}$, and day 11 onward for $T_{2}(0)=20^{\circ} \mathrm{C}$ (Figs. $4 \mathrm{a}$ and 5 ). For $T_{2}(0)=10^{\circ} \mathrm{C}$, the WRF single-moment, Goddard, and Morrison schemes all switch back into a sustained overcast or mostly cloudy state from the clear state, for days $4-11,8-14$, and 10-12, respectively. These three transitions are each associated with a physically deep layer of tenuous ice cloud that exceeds our $20 \mathrm{~g} \mathrm{~m}^{-2}$ criterion for cloud condensate path but has a weak longwave radiative effect and cannot prevent development of a surface inversion. The depth of these optically thin ice-cloud layers is probably exaggerated by the lack of large-scale dynamics (e.g., subsidence), but optically thin ice clouds are a common occurrence in the Arctic winter boundary layer (e.g., Curry et al. 1996).

\section{b. Time-mean cooling and cloud properties}

To synthesize many cooling time series such as those shown in Fig. 4, we define a metric of time-mean surface air cooling $\Delta T_{2}$ by

$$
\Delta T_{2}=T_{2}(0)-\overline{T_{2}(t)}
$$

where the overline on $T_{2}(t)$ indicates a time-mean over the 2-week simulation. Time-mean surface air cooling decreases nonlinearly with initial temperature, with relatively little spread across microphysics schemes (Fig. 6a), and is much greater for the no-CRF simulations (dashed-dotted line in Fig. 6a). A least squares fit of $\Delta T_{2}$ averaged over all microphysics schemes gives

$$
\Delta T_{2}=37-0.614 T_{2}(0)-0.0272 T_{2}(0)^{2}
$$

and for the no-CRF simulations gives

$$
\Delta T_{2}^{\mathrm{no}-\mathrm{CRF}}=40.4-0.239 T_{2}(0)-0.0095 T_{2}(0)^{2},
$$



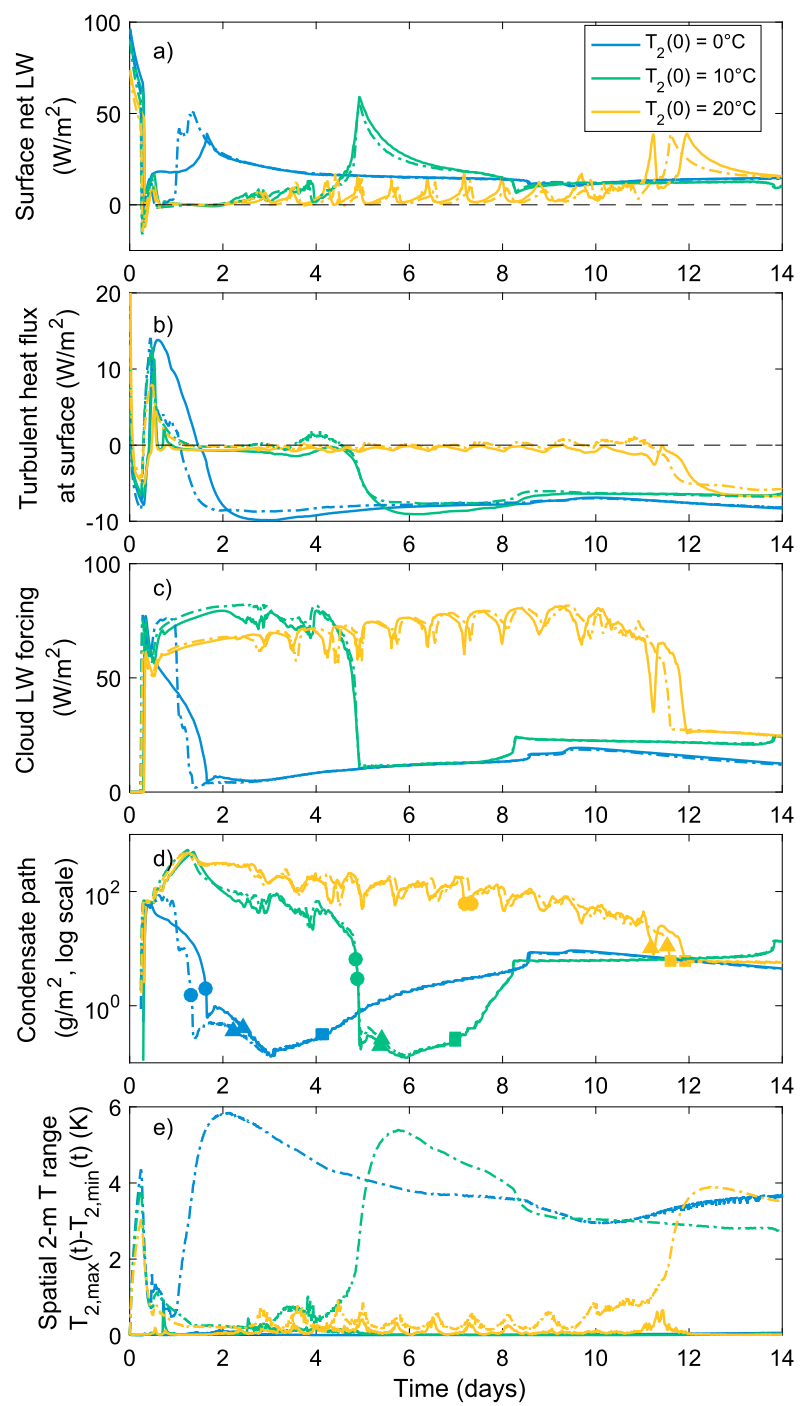

FIG. 3. Time series of surface energy balance in simulations with $T_{2}(0)=0^{\circ}, 10^{\circ}$, and $20^{\circ} \mathrm{C}$, using the Lin-Purdue microphysics scheme. Solid lines show results from normal Lin-Purdue simulations with uniform surface heat capacity, and dashed-dotted lines show results from simulations with heterogeneous heat capacity. (a) Net longwave cooling of the surface, (b) the total turbulent heat flux out of the surface (sensible plus latent), (c) the longwave cloud forcing at the surface, (d) the cloud condensate path for the entire depth of the troposphere (note log scale), and (e) spatial variability in 2-m air temperature, quantified as the difference between the maximum and minimum 2-m air temperatures at each time. Surface cloud longwave forcing in (c) is defined as the difference between the surface net longwave fluxes in hypothetical clear-sky and all-sky cases. In (d), filled markers show the points at which cloud water first crosses thresholds of $>10 \%$ ice (circles), $>50 \%$ ice (triangles), and $>90 \%$ ice (squares).

with $T_{2}(0)$ in degrees Celsius. The slope $\gamma=-\partial \Delta T_{2} / \partial T_{2}(0)$ is a dimensionless feedback measure that indicates the extent to which the Arctic air formation process amplifies initial surface air temperature differences. In the mean
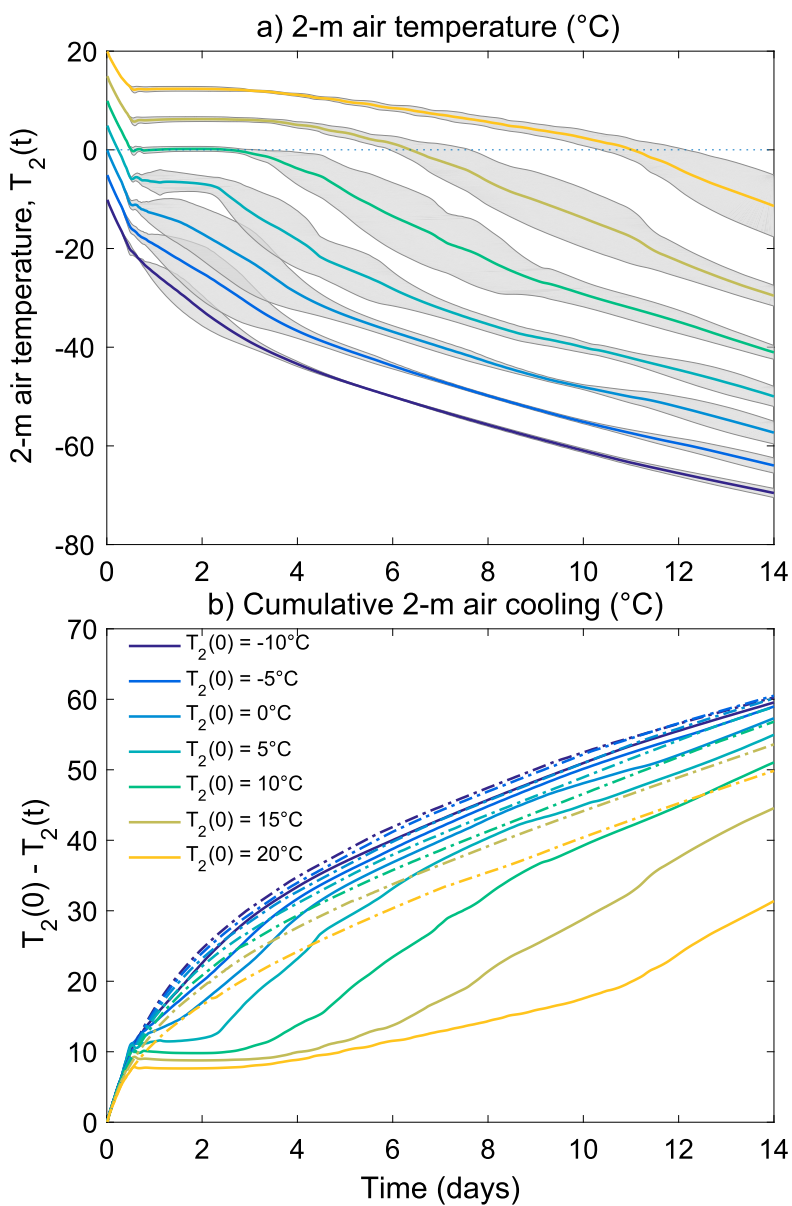

FIG. 4. Time series of (a) 2-m air temperature and (b) cumulative 2-m cooling $\left[T_{2}(0)-T_{2}(t)\right]$, for initial 2 -m temperatures from $-10^{\circ}$ to $20^{\circ} \mathrm{C}$ in $5^{\circ} \mathrm{C}$ increments, as labeled in (b). The solid colored lines in both panels represent an average over all cloud microphysics schemes; shaded regions in (a) indicate the variation among different microphysics schemes, excluding the no-CRF case (plus and minus one standard deviation). Dashed-dotted lines in (b) show cooling time series for the no-CRF simulation at each initial temperature.

across microphysics schemes, each degree of warming of the initial state leads to a decrease of time-mean surface air cooling by $\gamma=0.614+0.054 T_{2}(0)\left({ }^{\circ} \mathrm{C}\right)$. For example, for the warmest case $\left[T_{2}(0)=20^{\circ} \mathrm{C}\right]$, each degree of initial warming implies a $\gamma \approx 1.7^{\circ} \mathrm{C}$ decrease in average cooling. In comparison, the no-CRF feedback is about $65 \%$ smaller: $\gamma^{\text {no-CRF }}=0.239+0.019 T_{2}(0)\left({ }^{\circ} \mathrm{C}\right)$. Thus, cloud radiative effects alone reduce surface cooling by about a degree for each degree of warming of $T_{2}(0)$ in the warmest cases that we simulate.

The time for the 2-m temperature to reach freezing $\tau_{0}$ remains well under a day for all microphysics schemes when $T_{2}(0)$ is less than $8^{\circ} \mathrm{C}$. For a $2^{\circ} \mathrm{C}$ warming above $10^{\circ} \mathrm{C}\left(8^{\circ} \mathrm{C}\right.$ for the Goddard microphysics scheme), 


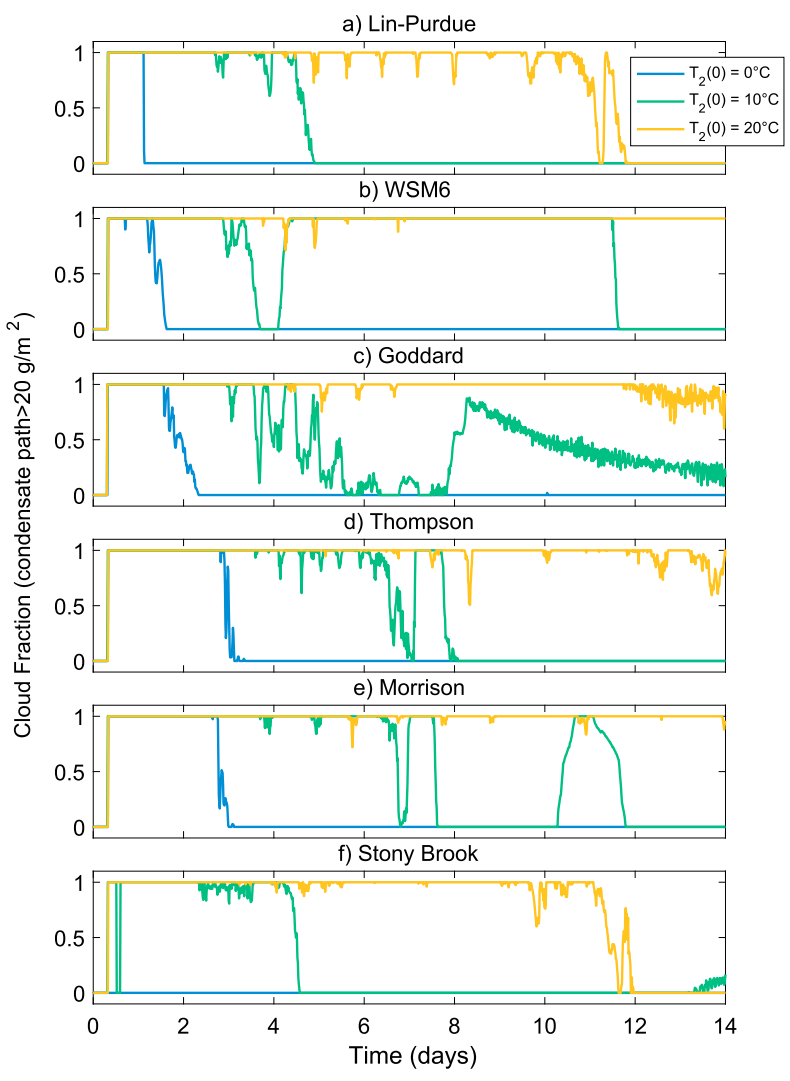

FIG. 5. Time series of cloud fraction in each microphysics scheme over 2-week simulations for $T_{2}(0)=0^{\circ}, 10^{\circ}$, and $20^{\circ} \mathrm{C}$. Cloud fraction is defined as the fraction of grid cells with a vertically integrated condensed water path of $20 \mathrm{~g} \mathrm{~m}^{-2}$ or greater, including both liquid and ice.

however, the time to freezing very rapidly jumps to 4-6 days, then increases further to 10-12 days for $T_{2}(0)=20^{\circ} \mathrm{C}$. The rapid jump and subsequent continued increase occur because of the shape of the cooling time series and because the time to freezing is the time to cross a fixed threshold of $0^{\circ} \mathrm{C}$ (Fig. 4a). When $T_{2}(0)$ is less than $10^{\circ} \mathrm{C}$, the surface drops below freezing during the period of rapid clear-sky cooling; for the warmer cases, clouds form before the surface has the chance to cool to freezing, and the threshold is crossed during a period of slow cooling. The abrupt jump in $\tau_{0}$ near $T_{2}(0)=10^{\circ} \mathrm{C}$ is thus an indicator of the flatness of the cooling time series in Fig. 4 a.

Time-mean cloud condensate path, dominated by cloud liquid path $\widehat{q_{\mathrm{cl}}}$, increases with warming across all microphysics schemes (Fig. 7a). Averaged across microphysics schemes, time-mean cloud liquid path increases from $\sim 10 \mathrm{~g} \mathrm{~m}^{-2}$ at $T_{2}(0)=0^{\circ} \mathrm{C}$ to $\sim 50 \mathrm{~g} \mathrm{~m}^{-2}$ at $T_{2}(0)=10^{\circ} \mathrm{C}$ to $\sim 125 \mathrm{~g} \mathrm{~m}^{-2}$ at $T_{2}(0)=20^{\circ} \mathrm{C}$. The spread across microphysics schemes is large, greater than a factor of 3 at all initial temperatures, but all schemes

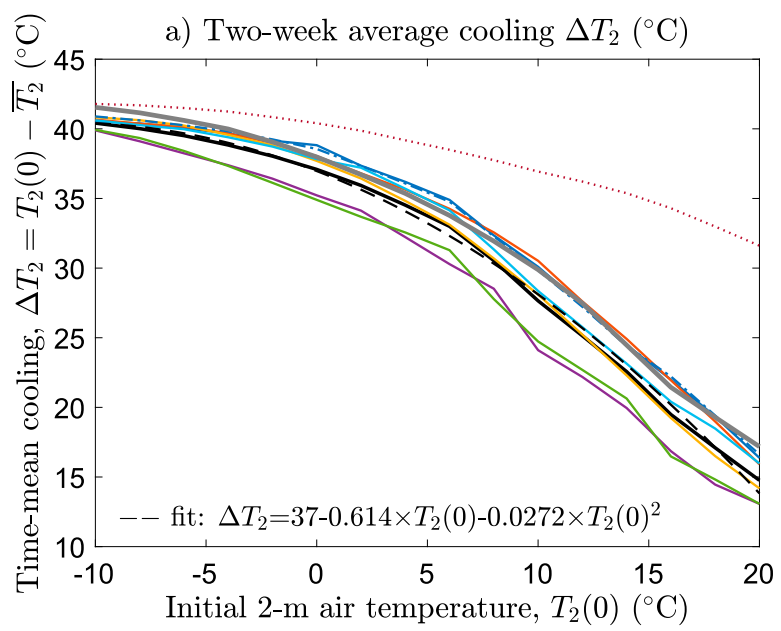

$\circlearrowright$ b) Time $\tau_{0}$ (days) taken for $T_{2}$ to drop below freezing

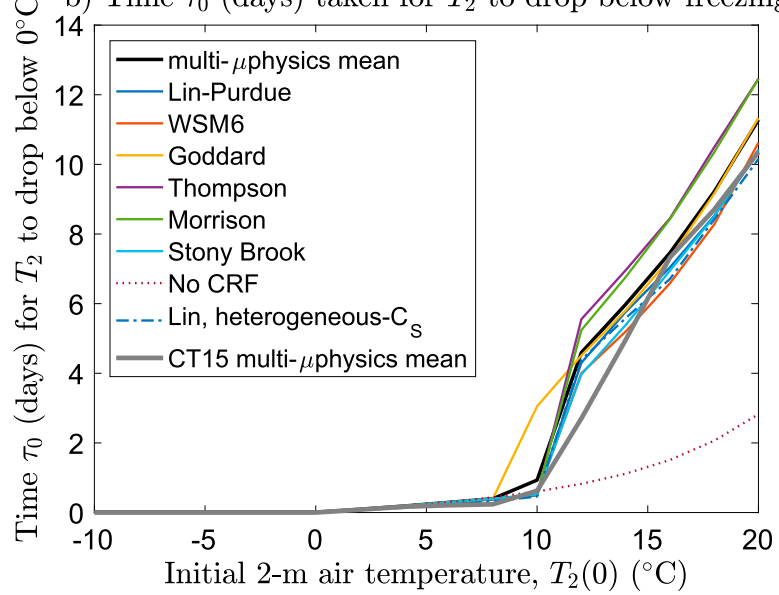

FIG. 6. (a) Average 2-m cooling over 2 weeks, defined as the difference between the initial 2-m temperature and the 2-m temperature averaged over the 2-week period and (b) the number of days for the 2-m temperature to drop to freezing. Both quantities are plotted for a range of initial 2-m air temperatures from $-10^{\circ} \mathrm{C}$ to $20^{\circ} \mathrm{C}$ in $2^{\circ} \mathrm{C}$ increments and several cloud microphysics schemes. The mean across microphysics schemes is shown in black, and the same quantity from Cronin and Tziperman (2015) is shown in gray for comparison.

nonetheless show large relative increases in cloud liquid path with warming. Although part of the increase occurs as a result of thickening of clouds in the opaquely cloudy state, most of this increase owes to an increasing fraction of the 2-week period spent in the opaquely cloudy state (Fig. 5). The increasing fraction of time spent in the cloudy state with warming can also be seen from Fig. 7c, which shows the temperature dependence of time-mean cloud fraction, defined as the fraction of grid cells for which total condensate path exceeds $20 \mathrm{~g} \mathrm{~m}^{-2}$ and averaged across all time steps. The timemean cloud fraction averaged across microphysics schemes increases from $\sim 10 \%$ at $T_{2}(0)=0^{\circ} \mathrm{C}$ to $\sim 90 \%$ at $T_{2}(0)=20^{\circ} \mathrm{C}$. Time-mean cloud ice path changes less 

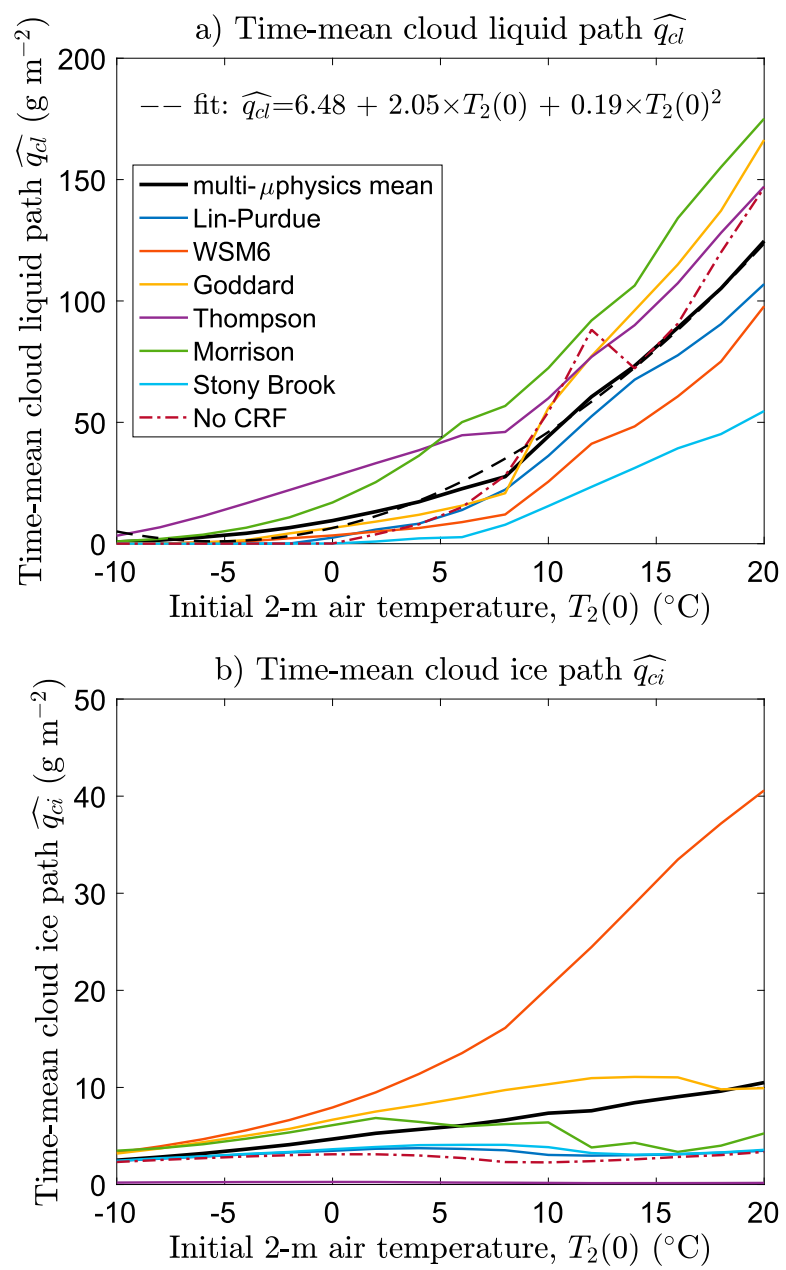

c) Time-mean cloud fraction $\left(\widehat{q_{c l}}+\widehat{q_{c i}}>20 \mathrm{~g} \mathrm{~m}^{-2}\right)$

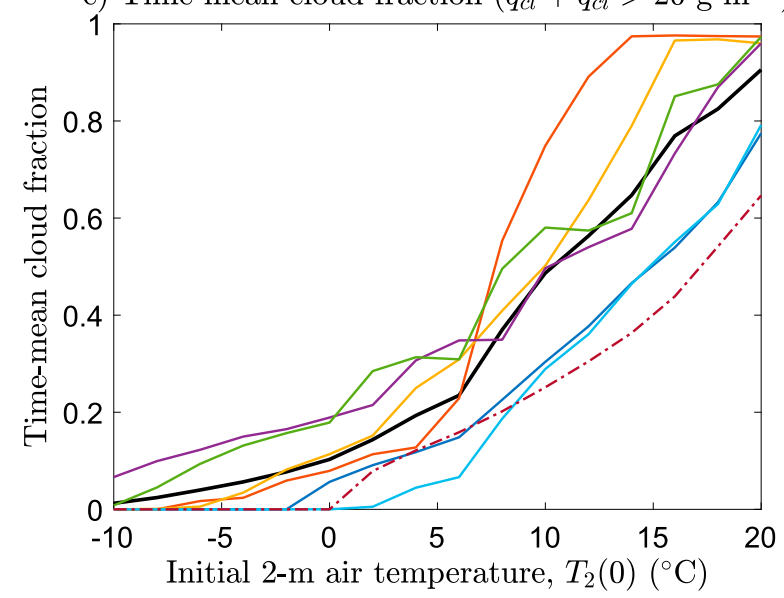

FIG. 7. (a) Time-mean cloud liquid path $\widehat{q_{\mathrm{cl}}}\left(\mathrm{g} \mathrm{m}^{-2}\right)$ and (b) timemean cloud ice path $\widehat{q_{\mathrm{ci}}}\left(\mathrm{g} \mathrm{m}^{-2}\right)$, each shown across the set of microphysics schemes and values of initial 2-m temperature $T_{2}(0)$. (c) The time-mean cloud fraction, defined as the fraction of grid cells for which total condensate path-both liquid and ice-exceeds $20 \mathrm{~g} \mathrm{~m}^{-2}$, averaged across all time steps. Each panel also shows the mean across microphysics schemes as a thick black line, and (a) shows a quadratic fit to the multimicrophysics mean of the cloud liquid path. consistently with warming than does cloud liquid path or cloud fraction (Fig. 7b). Outliers include the fivefold increase in cloud ice path from $8 \mathrm{~g} \mathrm{~m}^{-2}$ at $T_{2}(0)=0^{\circ} \mathrm{C}$ to $40 \mathrm{~g} \mathrm{~m}^{-2}$ at $T_{2}(0)=20^{\circ} \mathrm{C}$ in the WSM6 scheme and values of $<1 \mathrm{~g} \mathrm{~m}^{-2}$ of cloud ice path with nonmonotonic dependence on $T_{2}(0)$ in the Thompson scheme. The phase of cloud water that contributes to the cloud fraction (condensate path exceeding $20 \mathrm{~g} \mathrm{~m}^{-2}$ ) is almost entirely liquid for the Lin-Purdue, Thompson, Morrison, and Stony Brook schemes but ice as well for the Goddard scheme and especially the WSM6 scheme. Comparing Figs. 6 and 7, we see that the spread in 2-week average cooling across microphysics schemes is linked to the spread in cloud fraction and time-mean cloud liquid path, with the Thompson and Morrison schemes cooling least, the Goddard scheme close to the multimicrophysics mean, and the Lin-Purdue, WSM6, and Stony Brook schemes cooling the most.

Mean statistics averaged over time and across microphysics schemes are given in Table 1 for simulations with $T_{2}(0)$ in $\left\{-10^{\circ},-5^{\circ}, 0^{\circ}, 5^{\circ}, 10^{\circ}, 15^{\circ}, 20^{\circ}\right\} \mathrm{C}$ and will be discussed in more detail below. Note that the time-mean surface skin temperature $\overline{T_{S}}$ is $\sim 3^{\circ} \mathrm{C}$ colder than the time-mean surface air temperature $\overline{T_{2}}$ in the coldest simulations, because the strong surface inversion includes a near discontinuity between the surface and near-surface air (this surface temperature jump is weakened by about a third in sensitivity tests where the roughness length is increased from $\sim 2 \times 10^{-5}$ to $0.001 \mathrm{~m}$ ). Evolution of the surface temperature jump $T_{S}-T_{2}$ closely follows the surface turbulent heat flux, with slightly positive values in the opaquely cloudy state and negative values in the radiatively clear state. Because the cloudy state dominates for higher values of $T_{2}(0)$, the difference between surface skin temperature and surface air temperature is much reduced for the warmest simulations. Thus, a cooling metric defined in terms of time-mean surface skin temperature would be even more sensitive to the initial state than $\Delta T_{2}$.

\section{Discussion}

\section{a. Comparison of cloud-resolving and single-column model results}

The results above are both qualitatively and quantitatively consistent with the findings of Cronin and Tziperman (2015), who used a single-column setup of WRF. A key conclusion of this paper is to support the single-column model result that Arctic air formation is suppressed for a warm initial maritime profile.

Nevertheless, it is useful to analyze in depth the differences between single-column and cloud-resolving 
TABLE 1. Summary statistics for simulations with different initial temperatures averaged across microphysics schemes. Quantities prefaced with "time mean" are averaged over the whole 2-week period, and angle brackets indicate mass-weighted vertical integrals.

\begin{tabular}{|c|c|c|c|c|c|c|c|c|}
\hline \multirow[b]{2}{*}{ Quantity } & \multirow[b]{2}{*}{ Units } & \multicolumn{7}{|c|}{$T_{2}(0)\left({ }^{\circ} \mathrm{C}\right)$} \\
\hline & & -10 & -5 & 0 & 5 & 10 & 15 & 20 \\
\hline Time-mean 2-m temperature $\left[\overline{T_{2}(t)}\right]$ & ${ }^{\circ} \mathrm{C}$ & -50.2 & -44.0 & -36.9 & -28.6 & -17.5 & -5.8 & 5.4 \\
\hline Time-mean surface temperature $\left[\overline{T_{S}(t)}\right]$ & ${ }^{\circ} \mathrm{C}$ & -53.6 & -47.1 & -39.5 & -30.7 & -19.1 & -6.8 & 5.0 \\
\hline Time-mean atmospheric cooling rate & ${ }^{\circ} \mathrm{C}_{\text {day }}{ }^{-1}$ & 1.15 & 1.27 & 1.39 & 1.52 & 1.64 & 1.75 & 1.84 \\
\hline Time-mean condensation rate & $\mathrm{mm} \mathrm{day}^{-1}$ & 0.13 & 0.21 & 0.32 & 0.48 & 0.72 & 1.03 & 1.37 \\
\hline Change in atmospheric heat content $\left(c_{v} \Delta\langle T\rangle / \Delta t\right)$ & $\mathrm{W} \mathrm{m}^{-2}$ & -88.8 & -97.2 & -106.3 & -115.5 & -124.5 & -131.5 & -136.9 \\
\hline Change in atmospheric potential energy $(\Delta\langle g z\rangle / \Delta t)$ & $\mathrm{W} \mathrm{m}^{-2}$ & -18.2 & -19.8 & -21.3 & -22.6 & -23.1 & -22.3 & -19.7 \\
\hline Change in atmospheric latent energy $\left(L_{v} \Delta\left\langle q_{v}\right\rangle / \Delta t\right)$ & $\mathrm{W} \mathrm{m}^{-2}$ & -3.8 & -5.9 & -9.2 & -14.0 & -20.8 & -29.8 & -39.7 \\
\hline Change in surface heat content $\left(C_{S} \Delta T_{S} / \Delta t\right)$ & $\mathrm{W} \mathrm{m}^{-2}$ & -10.9 & -10.8 & -10.5 & -10.0 & -9.3 & -8.2 & -5.7 \\
\hline Time-mean energetic imbalance & $\mathrm{W} \mathrm{m}^{-2}$ & 2.65 & 2.22 & 1.66 & 0.99 & 0.27 & -0.64 & -0.71 \\
\hline Time-mean OLR & $\mathrm{W} \mathrm{m}^{-2}$ & 124.4 & 135.9 & 148.9 & 163.1 & 177.9 & 191.2 & 201.4 \\
\hline Initial OLR & $\mathrm{W} \mathrm{m}^{-2}$ & 192.6 & 203.9 & 215.5 & 227.7 & 240.4 & 253.9 & 268.1 \\
\hline Time-mean clear-sky OLR & $\mathrm{W} \mathrm{m}^{-2}$ & 120.8 & 131.9 & 144.7 & 159.7 & 179.2 & 200.4 & 221.4 \\
\hline Time-mean net longwave flux at surface & $\mathrm{W} \mathrm{m}^{-2}$ & 20.4 & 18.9 & 17.1 & 15.4 & 13.2 & 10.6 & 6.7 \\
\hline Time-mean net clear-sky longwave flux at surface & $\mathrm{W} \mathrm{m}^{-2}$ & 31.2 & 34.5 & 39.6 & 46.4 & 57.8 & 67.9 & 73.8 \\
\hline Time-mean surface sensible heat flux & $\mathrm{W} \mathrm{m}^{-2}$ & -9.39 & -8.17 & -6.67 & -5.45 & -4.10 & -2.62 & -1.03 \\
\hline Time-mean surface latent heat flux & $\mathrm{W} \mathrm{m}^{-2}$ & 0.01 & 0.03 & 0.08 & 0.08 & 0.09 & 0.11 & 0.12 \\
\hline Time-mean top-of-atmosphere CRF & $\mathrm{W} \mathrm{m}^{-2}$ & -3.5 & -4.0 & -4.1 & -3.4 & 1.3 & 9.2 & 20.0 \\
\hline Time-mean surface CRF & $\mathrm{W} \mathrm{m}^{-2}$ & 10.8 & 15.7 & 22.5 & 31.1 & 44.6 & 57.4 & 67.1 \\
\hline
\end{tabular}

results, to determine where differences lie. Our Fig. 6 shows in gray the multimicrophysics mean curves from Fig. 2 of Cronin and Tziperman (2015). For the cloudresolving simulations presented here, time-mean surface cooling over 2 weeks is slightly reduced (by $\sim 1-3^{\circ} \mathrm{C}$ ) and the feedback $\gamma$ is $3 \%-8 \%$ larger relative to the singlecolumn results. The cooling curves are less flat for warm $T_{2}(0)$ in the simulations of Cronin and Tziperman (2015) as compared to the results found here, so the sharp jump in $\tau_{0}$ around $T_{2}(0)=10^{\circ} \mathrm{C}$ was not found in Cronin and Tziperman (2015). These differences could result from numerical issues, such as changes in domain height and vertical level spacing, or from physical differences between the cloud-resolving and single-column models related to changes in clouds and turbulence.

To compare single-column and cloud-resolving results more directly, we have rerun single-column simulations with the same vertical level spacing (301 vertical levels, model top at $15 \mathrm{~km}$ ) used here in all of our twodimensional simulations. Figure 8 shows differences in time-mean surface air temperature between cloudresolving and single-column simulations, $\bar{T}_{2}{ }^{2 \mathrm{D}}-{\overline{T_{2}}}^{\mathrm{SCM}}$, as well as differences in time-mean cloud condensate amount and time-mean cloud fraction. Differences are small at low $T_{2}(0)$ for all but the Morrison scheme but generally grow for warmer initial atmospheric states [some schemes have greatest disagreement for $T_{2}(0)=$ $\left.10-15^{\circ} \mathrm{C}\right]$. Cloud-resolving simulations are generally warmer near the surface than single-column simulations (Fig. 8a), by $\sim 2^{\circ} \mathrm{C}$ in the mean across microphysics schemes for initial 2-m temperatures above $10^{\circ} \mathrm{C}$, and by up to $5^{\circ} \mathrm{C}$ for the Morrison scheme. Surface air temperature differences between the cloud-resolving and singlecolumn models also have strong time dependence, with most warming at times when the cloud-resolving model still has optically thick clouds but the single-column model clouds have dissipated (not shown).

Warmer surface conditions in the cloud-resolving simulations are associated with a larger time-mean cloud liquid path and cloud fraction (Figs. 8b,d). The difference in cloud fraction is $\sim 0.1$ in the mean across microphysics schemes for $T_{2}(0)>10^{\circ} \mathrm{C}$, with the cloudresolving model maintaining cloud layers for considerably longer than the single-column model, especially in the Thompson and Morrison schemes. The Goddard scheme is an outlier, in that it has less cloud liquid and ice and a smaller cloud fraction in the two-dimensional simulations than in the single-column simulations, yet it still maintains a modestly warmer surface at higher initial temperatures. The pattern of overall differences in both temperature and cloud condensate between cloudresolving and single-column simulations indicates more active cloud-top turbulence and entrainment in the cloud-resolving simulations, leading to cloud layers that grow more rapidly and ultimately become deeper and condense more water than in the single-column simulations [this difference occurs for all microphysics schemes at $T_{2}(0)=20^{\circ} \mathrm{C}$ ]. Because the radiative cooling to space from lower-tropospheric cloud tops is spread over a deeper layer, cooling is weaker at the surface but 


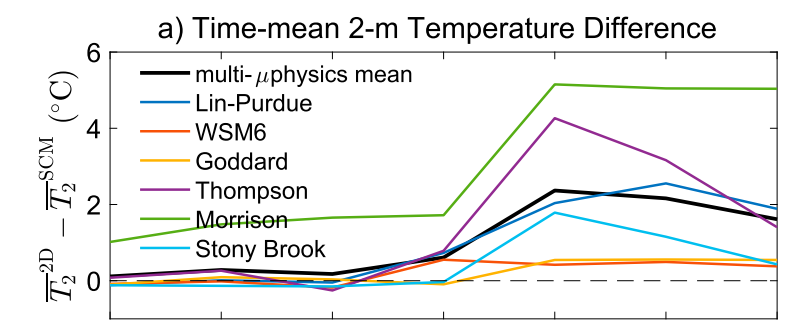

b) Time-mean cloud liquid path difference

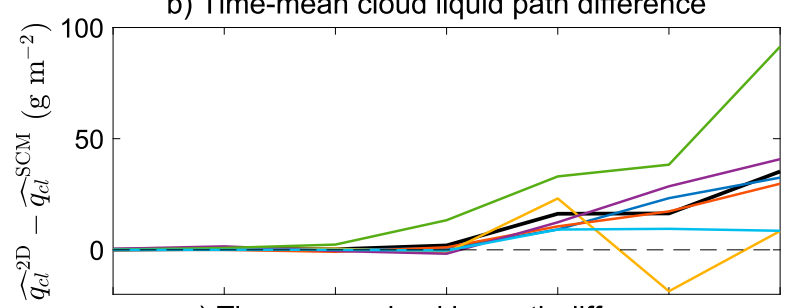

c) Time-mean cloud ice path difference
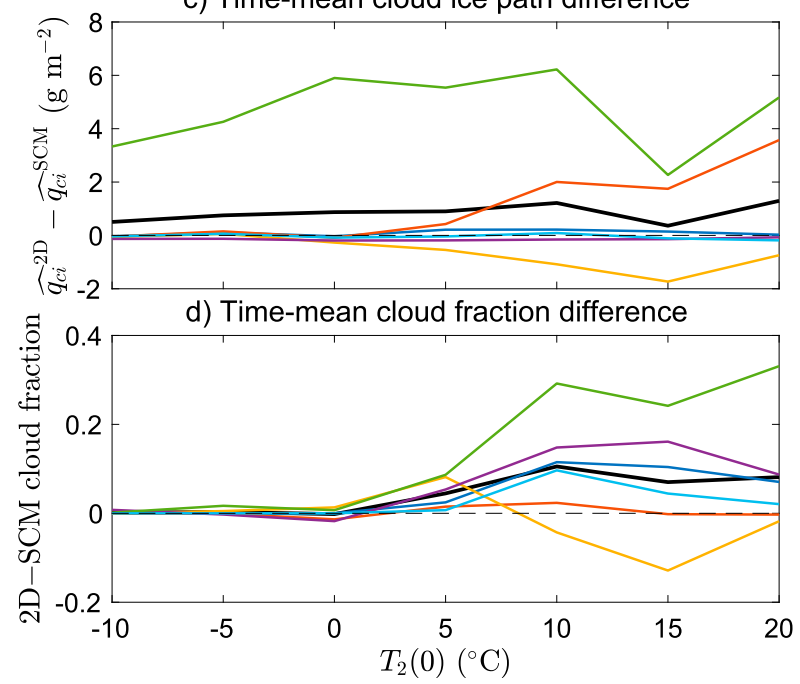

FIG. 8. Difference in surface air temperature and cloud statistics between two-dimensional simulations and analogous single-column model simulations as a function of the initial temperature, quantified by (a) time-mean 2-m temperature difference $\left(\bar{T}_{2}^{2}{ }^{2 \mathrm{D}}-{\overline{T_{2}}}^{\mathrm{SCM}}\right)\left({ }^{\circ} \mathrm{C}\right)$, (b) time-mean cloud liquid path difference $\left({\widehat{q_{\mathrm{cl}}}}^{2 \mathrm{D}}-{\widehat{q_{\mathrm{cl}}}}^{\mathrm{SCM}}\right)\left(\mathrm{g} \mathrm{m}^{-2}\right)$, (c) time-mean cloud ice path difference $\left({\widehat{q_{\mathrm{ci}}}}^{2 \mathrm{D}}-{\widehat{q_{\mathrm{ci}}}}^{\mathrm{SCM}}\right)\left(\mathrm{g} \mathrm{m}^{-2}\right)$, and (d) time-mean cloud fraction difference (2D minus SCM). Mean across microphysics schemes is shown as a thick black line in each panel.

extends to greater height, with additional warmth near the surface offset by colder conditions near the highest cloud-top inversion. Thus, in spite of our initial expectation that a cloud-resolving model might give more surface cooling because it allows for cloud layers with less than $100 \%$ cover, it appears that the reverse occurs as a result of increasing cloud condensate, cloud fraction, and cloud-layer thickness.

The differences between cloud-resolving and singlecolumn model simulations are relatively small when compared with the overall changes to the process of Arctic air formation with climate warming. The largest differences, however, occur for the Thompson and Morrison schemes, which seem to give the most credible mixed-phase clouds. Using a two-dimensional model rather than a single-column model leads to a $\sim 50 \%$ increase in $\gamma$ for both of these schemes for $T_{2}(0)$ of $0^{\circ}-10^{\circ} \mathrm{C}$. Comparing two-dimensional and singlecolumn model results thus suggests that modest warming of the present climate may lead to stronger suppression of Arctic air formation than was previously found by Cronin and Tziperman (2015).

\section{b. Vertical structure of cooling}

As the initial atmospheric state is warmed, the surface cooling rate decreases, but the top-of-atmosphere outgoing longwave radiation increases. Reconciling these opposing tendencies requires that the cooling rate of the atmosphere must increase with $T_{2}(0)$ at some height above the surface. Plotting the profile of average cooling rate, we indeed see that cooling decreases with $T_{2}(0)$ at and just above the surface, but increases with $T_{2}(0)$ above the lowermost troposphere (Fig. 9). The strongest reduction in surface cooling as $T_{2}(0)$ is increased occurs over the first week of the simulation (Fig. 9a), with a nonmonotonic response of surface cooling to $T_{2}(0)$ during the second week (Fig. 9b). Colder initial atmospheres have a surface cooling rate of $\sim 4^{\circ} \mathrm{C} \mathrm{day}^{-1}$ over the 2-week period and $\sim 5^{\circ} \mathrm{C} \mathrm{day}^{-1}$ during the first week, but the atmosphere above $850 \mathrm{hPa}$ cools at $2^{\circ} \mathrm{Cday}^{-1}$ or less. The warmest cases $\left[T_{2}(0)=20^{\circ} \mathrm{C}\right]$ have a cooling rate of about $2^{\circ} \mathrm{Cday}^{-1}$ that is relatively constant in time and height over a deep layer (up to approximately $300 \mathrm{hPa}$ ). There is significant spread across microphysics schemes in the timing of cooling, as shown by the shaded areas in the plots of cooling broken down by week (Fig. 9a,b), but the total amount of cooling over the 2-week period differs much less (Fig. 9c). The mass-weighted average cooling rate of the atmosphere increases with $T_{2}(0)$, from $1.4^{\circ} \mathrm{Cday}^{-1}$ at $T_{2}(0)=0^{\circ} \mathrm{C}$ to $1.8^{\circ} \mathrm{C}$ ayy $^{-1}$ at $T_{2}(0)=20^{\circ} \mathrm{C}$ (Table 1 ). This cooling rate is an average temperature change from the sum of all physical processes simulated (radiation, condensation, and convection), and although it is dominated by longwave radiative cooling, it should not be interpreted as a radiative cooling rate alone. Surface cooling rates in the no-CRF simulations show much less sensitivity to the initial atmospheric temperature, with $\sim 4^{\circ}-5^{\circ} \mathrm{C}$ day $^{-1}$ surface cooling over the first week and $\sim 2^{\circ}-3^{\circ} \mathrm{C}_{\text {day }}{ }^{-1}$ surface cooling over the second week, and surface-amplified cooling over the whole 2-week period (Fig. 10). Although not obvious from comparison of Figs. 9 and 10, no-CRF simulations cool less above the inversion layer, by $\sim 0.25^{\circ} \mathrm{Cday}^{-1}$ at $800 \mathrm{hPa}$ over the full 2-week period; cloud-radiation interactions thus 

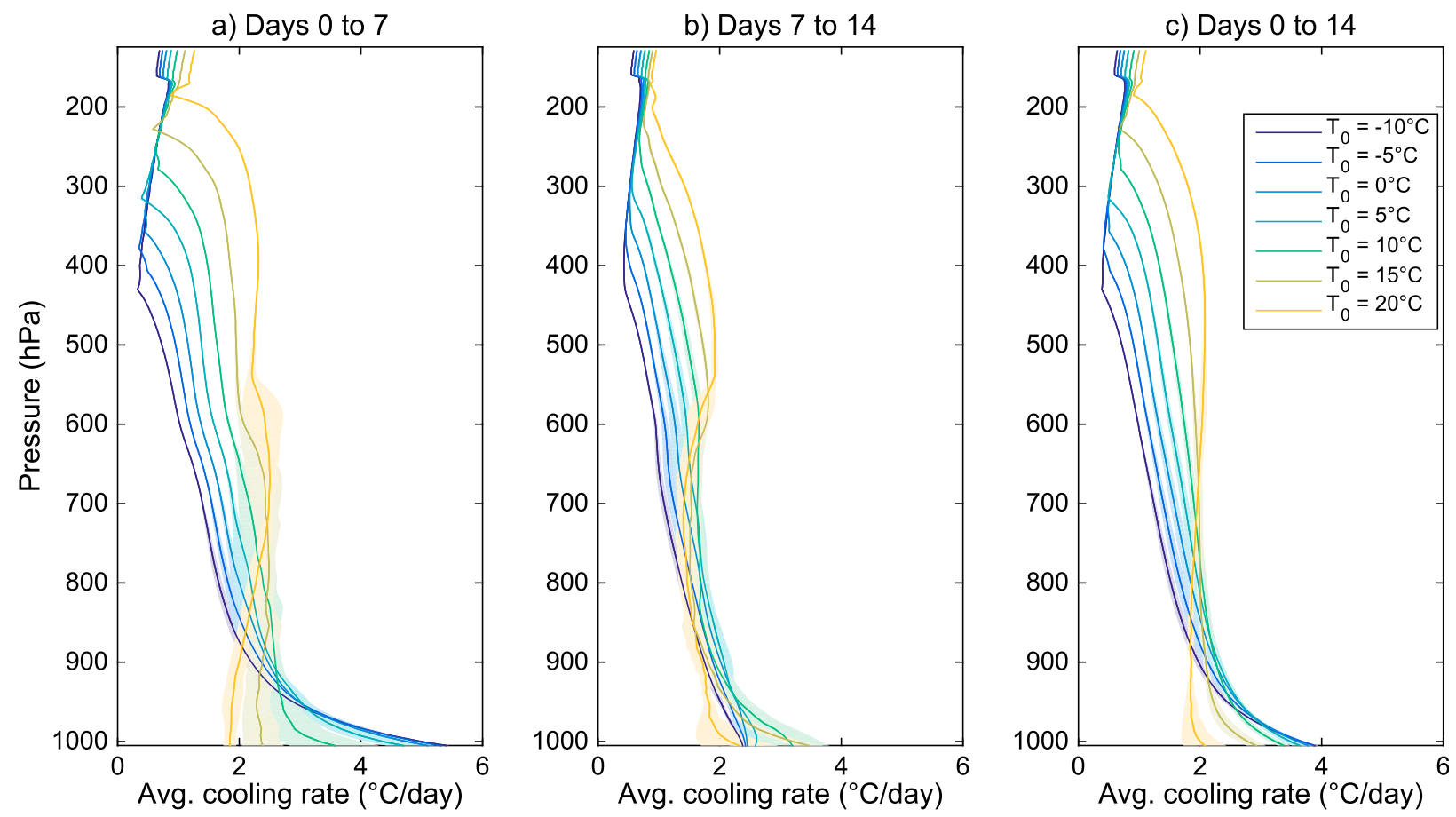

FIG. 9. Vertical profiles of total cooling rate averaged across microphysics schemes, as a function of initial 2-m air temperature for (a) the first week, (b) the second week, and (c) both weeks. Solid lines represent averages across microphysics schemes, and the shaded area indicates the spread across microphysics schemes (plus and minus one standard deviation).

weaken the surface inversion but shift cooling upward, to the tops of optically thick clouds, or to the whole layer spanned by optically thin clouds. An upward shift and increase in magnitude of mid- and upper-tropospheric cooling with warming of the initial atmosphere is seen in simulations with and without cloud-radiation interactions (cf. Figs. 9 and 10 above $600 \mathrm{hPa}$ ).

The energy loss of the atmosphere and surface by radiation to space can be divided into contributions from changes in internal heat, latent, and gravitational potential energy of the atmosphere and changes in heat content of the surface (Table 1; angle brackets indicate mass-weighted vertical integrals). Condensation $\left(L_{v} \Delta\left\langle q_{v}\right\rangle / \Delta t\right)$ plays an increasingly important role in the column energy budget at the warmest temperatures, amounting to $\sim 40 \mathrm{~W} \mathrm{~m}^{-2}$ of heating in the warmest cases. For extremely warm initial temperatures, the role of condensation alone in increasing the effective heat capacity of the atmosphere could lead to a reduction in average tropospheric cooling rates with increasing $T_{2}(0)$ (Cronin and Emanuel 2013), but our simulations do not reach that limit, in part because our initial soundings are rather dry. Note that changes in internal heat energy $\left(c_{v} \Delta\langle T\rangle / \Delta t\right)$ and gravitational potential energy $(\Delta\langle g z\rangle / \Delta t)$ of the column do not sum to $c_{p} \Delta\langle T\rangle / \Delta t$, because the upper bound of integration is only $\sim 15 \mathrm{~km}$, and the equality only holds for a full column integral (e.g., Peixoto and Oort 1992, chapter 13). Loss of heat by the surface, $C_{S} \Delta T_{S} / \Delta t$, supplies $\lesssim 10 \mathrm{~W} \mathrm{~m}^{-2}$ to the atmosphere; the magnitude of this term is limited because the surface heat capacity is small by design $\left(C_{S}=2.1 \times\right.$ $10^{5} \mathrm{~J} \mathrm{~m}^{-2} \mathrm{~K}^{-1}$ ).

\section{c. Top-of-atmosphere radiation and feedbacks}

To attempt to compare our results with the feedbacks diagnosed from global climate models (e.g., Pithan and Mauritsen 2014), we can analyze how top-ofatmosphere outgoing longwave radiation (OLR) depends on surface temperature. The main idea is similar to a climate model feedback analysis: that the derivative of OLR with respect to $T_{S}$ is a measure of the total radiative feedback, or how strongly top-of-atmosphere energy loss tends to damp surface warming. Because our model for Arctic air formation is an idealized depiction of a complex transient process, this analysis is not equivalent to a climate model feedback analysis, and we do not decompose the sensitivity of OLR to surface temperature $T_{S}$ into specific feedbacks: for example, Planck, lapse rate, water vapor, and cloud (such a decomposition would also require additional radiative transfer calculations outside of WRF). We infer from this analysis that there are strong positive cloud and clear-sky feedbacks associated with suppression of Arctic air formation that make $d \mathrm{OLR} / d T_{S}$ much smaller 
a) Days 0 to 7

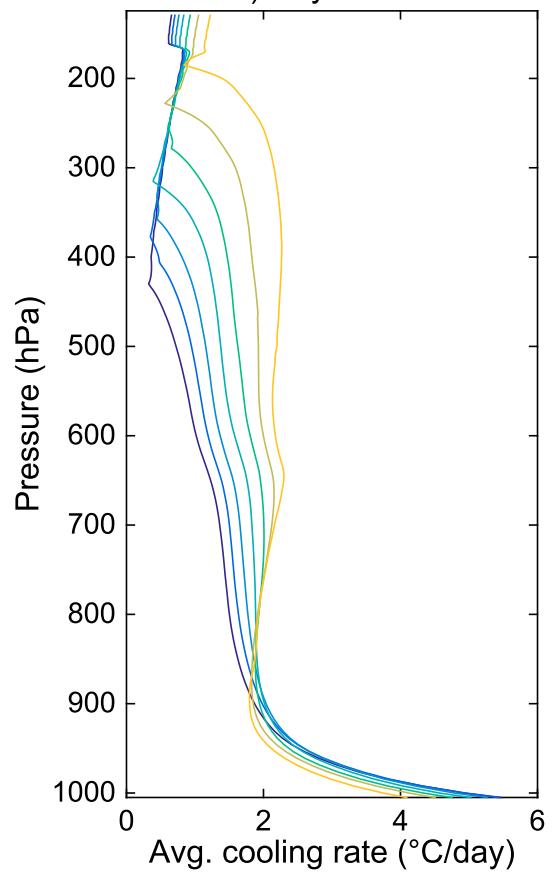

b) Days 7 to 14

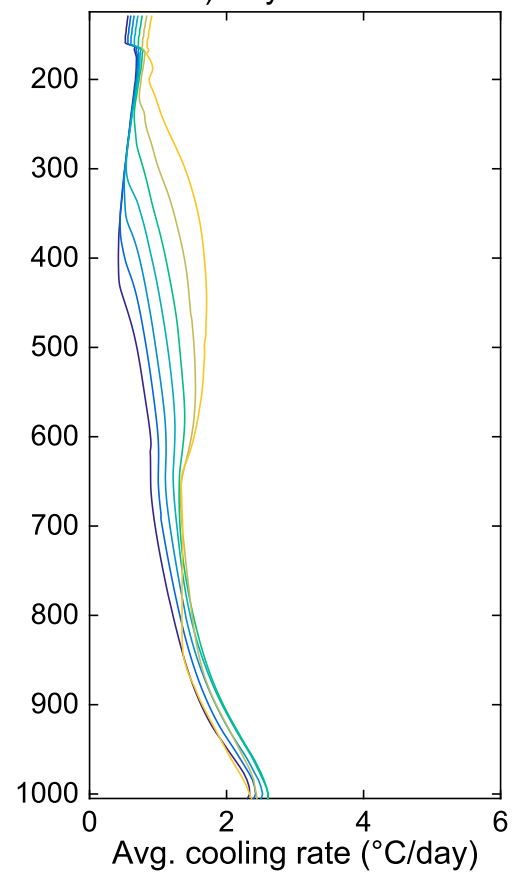

c) Days 0 to 14

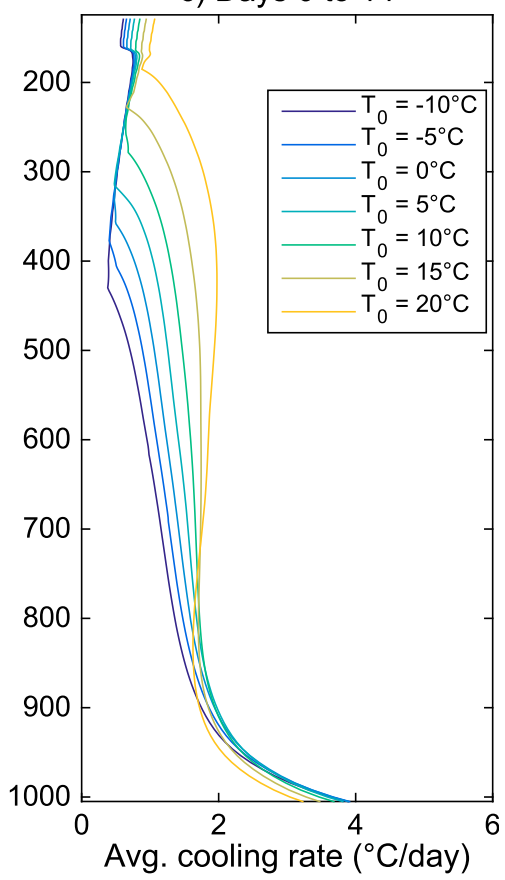

FIG. 10. Vertical profiles of total cooling rate for clear-sky radiation simulations (no-CRF) as a function of initial 2-m air temperature for (a) the first week, (b) the second week, and (c) both weeks.

in magnitude (less negative) for the time-mean atmospheric states (during the process of Arctic air formation) as compared to the initial atmospheric states.

Figure 11a shows the surface temperature dependence of three choices of OLR: initial OLR(0) plotted against initial surface temperature, time-mean clear-sky $\overline{\mathrm{OLR}}_{\text {clear }}$ plotted against time-mean surface temperature, and time-mean all-sky $\overline{\mathrm{OLR}}$ plotted against time-mean surface temperature (values also given in Table 1). A blackbody with temperature $25^{\circ} \mathrm{C}$ less than the surface is also plotted for reference as an example with only the Planck feedback present. Denoting the negative slope of OLR with respect to surface temperature as a feedback, we then also have three different feedback metrics for our simulations, corresponding to each choice of OLR:

$$
\begin{aligned}
\lambda(0) & =-\frac{d \mathrm{OLR}(0)}{d T_{S}(0)} \\
\bar{\lambda}_{\text {clear }} & =-\frac{d \overline{\mathrm{OLR}}_{\text {clear }}}{d \bar{T}_{S}} \\
\bar{\lambda} & =-\frac{d \overline{\mathrm{OLR}}}{d \overline{T_{S}}} .
\end{aligned}
$$

These feedback parameters are plotted with negative signs and represent a stabilizing total longwave feedback in all cases: a warmer atmosphere and surface lead to more OLR (Fig. 11b). The contrast in the feedback parameter $\lambda$, and its temperature dependence, between the time-mean and initial OLR values provides a measure of how the suppression of cold-air formation alters the local top-of-atmosphere longwave feedback. We wish to emphasize a few features of Fig. 11b:

- The longwave feedback in the initial state $\lambda(0)$ increases in magnitude from $-2.2 \mathrm{~W} \mathrm{~m}^{-2} \mathrm{~K}^{-1}$ for the coldest initial temperatures to $-2.8 \mathrm{~W} \mathrm{~m}^{-2} \mathrm{~K}^{-1}$ for the warmest, presumably because of negative Planck and lapse-rate radiative feedbacks, which increase in strength with warming of the initial state.

- The longwave clear-sky feedback in the time-mean state $\bar{\lambda}_{\text {clear }}$ has a near-constant value $\sim-1.7 \mathrm{~W} \mathrm{~m}^{-2} \mathrm{~K}^{-1}$. The smaller magnitude of $\bar{\lambda}_{\text {clear }}$ relative to $\lambda(0)-$ by $\sim 0.5 \mathrm{~W} \mathrm{~m}^{-2} \mathrm{~K}^{-1}$ in the range of overlapping temperature-indicates that there are positive clearsky OLR feedbacks associated with the suppression of Arctic air formation. We interpret this offset between $\bar{\lambda}_{\text {clear }}$ and $\lambda(0)$ as primarily a positive lapse-rate feedback, though we cannot rule out a water vapor feedback component.

- The longwave all-sky feedback in the time-mean state $\bar{\lambda}$ decreases in magnitude from $-1.9 \mathrm{~W} \mathrm{~m}^{-2} \mathrm{~K}^{-1}$ for the coldest initial temperatures to $-0.9 \mathrm{~W} \mathrm{~m}^{-2} \mathrm{~K}^{-1}$ for the warmest. The smaller magnitude of the feedback $\bar{\lambda}$ 

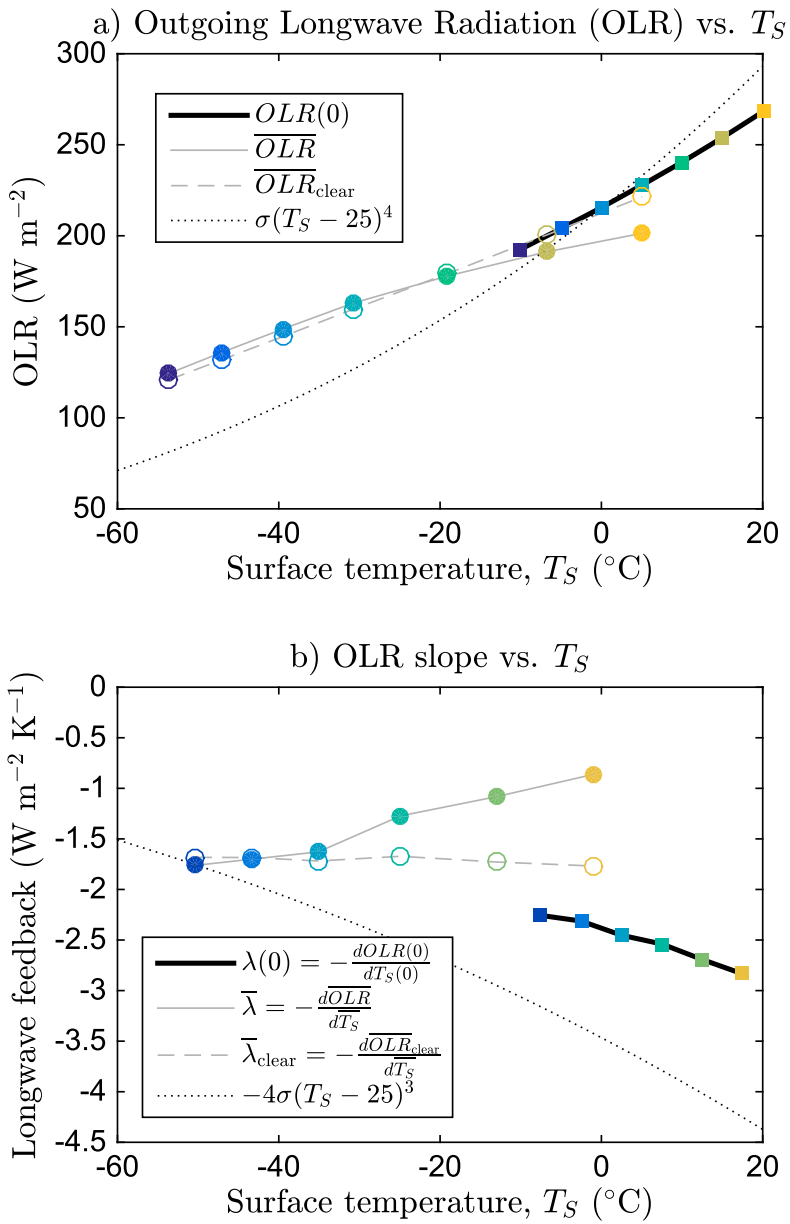

FIG. 11. (a) OLR as a function of surface temperature for initial conditions $[\mathrm{OLR}(0)]$, time-mean values $(\overline{\mathrm{OLR}})$, and time-mean clear-sky values $\left(\overline{\mathrm{OLR}}_{\text {clear }}\right)$. (b) Feedbacks based on slopes of OLR [from (a)] with respect to $T_{S}$. Progressively less negative values of $\bar{\lambda}_{\text {clear }}$ and $\bar{\lambda}$ relative to $\lambda(0)$ in (b) indicate positive cloud and clearsky feedbacks associated with suppression of Arctic air formation from warmer initial states. A blackbody with temperature $25^{\circ} \mathrm{C}$ lower than the surface $\left(T_{S}-25\right)$ is shown as dotted lines to provide reference values for (a) OLR and (b) the Planck feedback by itself.

with warming is due to a positive top-of-atmosphere cloud longwave feedback that rapidly increases to $\sim 1 \mathrm{~W} \mathrm{~m}^{-2} \mathrm{~K}^{-1}$ for the warmest initial conditions (cf. $\bar{\lambda}$ and $\bar{\lambda}_{\text {clear }}$ in Fig. 11b).

The strong top-of-atmosphere cloud feedback under warm conditions shown in Fig. 11b can also be inferred from time-mean top-of-atmosphere cloud radiative forcing, which is generally small compared to the surface cloud radiative forcing (and can even be negative), but which increases rapidly with warming for warm initial atmospheres (Table 1, bottom two rows). From a conventional top-of-atmosphere standpoint, clouds may thus act as a stronger positive feedback than was realized by Cronin and Tziperman (2015). Our results thus support the potentially important role of positive top-ofatmosphere longwave cloud feedback, particularly in much warmer climates (e.g., Abbot et al. 2009).

\section{$d$. Treatment of the surface and other limitations}

The surface in our model is treated very simply, essentially as a heat-storing slab that is dragged along with the atmosphere as it moves. By using identical values of $T_{S}(0)$ and $T_{2}(0)$ and giving the surface a relatively low heat capacity, we have tried to minimize biases in sensitivity $\gamma=-\partial \Delta T_{2} / \partial T_{2}(0)$ that might be related to the surface, although one clear limitation of this work is that properties of the surface do not change at all with temperature, even though major changes in real surface properties occur across the freezing point. Cronin and Tziperman (2015) found that a surface with higher heat capacity leads to smaller values of $\gamma$, whereas a surface with a lower heat capacity leads to a larger $\gamma$. We speculate that greater surface heat capacity will generally make surface temperatures less sensitive to changes in initial atmospheric state. This would have implications for previous work by Curry (1983), Pithan et al. (2014), and Pithan et al. (2016), who used a sea ice-like surface, with a prescribed thickness and temperature profile. Such a structural choice makes sense for exploring Arctic air formation in the present climate but likely makes $\gamma$ smaller than in our work, because ice with a prescribed temperature that is independent of the initial 2-m air temperature will conduct heat out of a warm initial atmosphere or into a cold initial atmosphere.

Our default model resolution $(\Delta x, \Delta z)=(100,50) \mathrm{m}$ has allowed us to run a large number of simulations across different microphysics schemes and temperatures but may be insufficient to fully resolve the liquid layer at the top of Arctic mixed-phase clouds (e.g., Ovchinnikov et al. 2014) and the sharpness of inversions that form near stratus cloud tops (e.g., Blossey et al. 2013). Sensitivity tests with varied resolution using the Lin-Purdue scheme at $T_{2}(0)$ of $0^{\circ}$ and $20^{\circ} \mathrm{C}$ show that altering the horizontal resolution by a factor of 2 typically leads to a change of a few watts per square meter in surface cloud forcing and $\sim 1^{\circ} \mathrm{C}$ in time-mean surface air temperature and that decreasing the resolution for a cold initial state can completely suppress the low-level turbulence (Table 2). Increasing vertical resolution leads to surface warming for $T_{2}(0)=20^{\circ} \mathrm{C}$ but to surface cooling for $T_{2}(0)=0^{\circ} \mathrm{C}$. This reversal occurs because the cloudy state dominates in the warm simulation, but the clear state dominates in the cold simulation, and its sharp surface inversions are strengthened at high vertical resolution. The Thompson and Morrison schemes, which simulate better mixed-phase clouds at low 
TABLE 2. Comparison of simulations with varied grid spacing. Metrics for comparison are the time-mean $2-\mathrm{m}$ air temperature $\left(\overline{T_{2}} ;{ }^{\circ} \mathrm{C}\right)$, the time-mean surface cloud radiative forcing $\left(\overline{\mathrm{CRF}}_{\mathrm{S}} ; \mathrm{W} \mathrm{m}{ }^{-2}\right)$, and the time-mean standard deviation of the instantaneous zonal wind, averaged over levels between 1000 and $850 \mathrm{hPa}\left(\overline{\sigma_{u}} ; \mathrm{m} \mathrm{s}^{-1}\right)$. Values in parentheses indicate deviations from the respective control simulation. Simulations shown use the Lin-Purdue microphysics scheme, with initial 2-m temperatures of $T_{2}(0)=0^{\circ} \mathrm{C}$ and $T_{2}(0)=20^{\circ} \mathrm{C}$.

\begin{tabular}{|c|c|c|c|c|c|c|c|}
\hline \multirow[b]{2}{*}{ Simulation } & \multirow[b]{2}{*}{ Grid spacing $(\Delta x, \Delta z)(\mathrm{m})$} & \multicolumn{3}{|c|}{$T_{2}(0)=0^{\circ} \mathrm{C}$} & \multicolumn{3}{|c|}{$T_{2}(0)=20^{\circ} \mathrm{C}$} \\
\hline & & $\overline{T_{2}}\left({ }^{\circ} \mathrm{C}\right)$ & $\overline{\mathrm{CRF}}_{\mathrm{S}}\left(\mathrm{W} \mathrm{m}^{-2}\right)$ & $\overline{\sigma_{u}}\left(\mathrm{~m} \mathrm{~s}^{-1}\right)$ & $\overline{T_{2}}\left({ }^{\circ} \mathrm{C}\right)$ & $\overline{\mathrm{CRF}}_{\mathrm{S}}\left(\mathrm{W} \mathrm{m}^{-2}\right)$ & $\overline{\sigma_{u}}\left(\mathrm{~m} \mathrm{~s}^{-1}\right)$ \\
\hline Control & $(100,50)$ & -38.83 & 15.34 & 0.010 & 3.63 & 61.71 & 0.204 \\
\hline $5 \times$ horizontal & $(500,50)$ & $-38.5(0.28)$ & $11.5(-3.87)$ & $0.001(-0.009)$ & $2.0(-1.58)$ & $58.9(-2.85)$ & $0.169(-0.035)$ \\
\hline $2.5 \times$ horizontal & $(250,50)$ & $-38.5(0.33)$ & $11.5(-3.85)$ & $0.001(-0.009)$ & $2.2(-1.45)$ & $59.2(-2.48)$ & $0.168(-0.036)$ \\
\hline $1 / 2 \times$ horizontal & $(50,50)$ & $-37.3(1.54)$ & $18.1(2.81)$ & $0.019(0.010)$ & $4.0(0.36)$ & $62.9(1.22)$ & $0.183(-0.021)$ \\
\hline $2 \times$ vertical & $(100,100)$ & $-37.1(1.68)$ & $16.2(0.90)$ & $0.015(0.006)$ & $2.6(-1.03)$ & $57.5(-4.24)$ & $0.173(-0.030)$ \\
\hline $1 / 2 \times$ vertical & $(100,25)$ & $-39.5(-0.67)$ & $16.1(0.78)$ & $0.026(0.016)$ & $3.7(0.11)$ & $62.9(1.20)$ & $0.208(0.004)$ \\
\hline
\end{tabular}

temperature, might be more sensitive to resolution for cold initial states. Use of two-dimensional rather than three-dimensional geometry is also a limitation of this study; we originally imagined that the upscale cascade of turbulent kinetic energy in two dimensions might allow for larger-scale circulations to develop and disrupt layered clouds, but it is not clear to what extent this occurred in any of our simulations.

Another limitation of this work is the lack of large-scale subsidence or wind shear. Moderate subsidence in singlecolumn simulations of Cronin and Tziperman (2015) was found to limit the upward growth of the cloud layer but did little to modify the suppression of Arctic air formation in a warmer initial atmosphere; we anticipate similar sensitivity to subsidence in the cloud-resolving model used here. A stochastically varying vertical velocity profile that includes stronger ascent and stronger subsidence, as in Brient and Bony (2013), might provide a stronger and more realistic test of our mechanism than steady subsidence. Regarding wind shear, we expect more rapid horizontal advection of air aloft than near the surface, so realistic vertical shear would likely lead to less cooling in the mid- and upper troposphere as an air mass traverses a continent than we have simulated here. The 2-week time period during which we follow the cold air formation process is also somewhat arbitrary and should be informed by investigation of the observed time scales of continental traversal for air parcels in the lower troposphere and projections of how these time scales may change with warming. Recent work by Woods and Caballero (2016) has suggested a link between observed Arctic warming and increasing frequency of injection events of very warm and moist air into the polar region: a result consistent with the ideas presented in this paper. Questions about the role of large-scale dynamics-both vertical advection and the statistics of horizontal flowpoint to investigation of cold-air formation in a global climate model as a productive future research direction.

An additional limitation was noted above: in the version of WRF we use, the coupling between radiation and microphysics is incomplete. Only the total liquid and ice content in each column and vertical level are passed from the microphysics scheme to the radiation scheme, and the radiation scheme makes its own assumptions about cloud particle sizes. The spread across microphysics schemes shown here thus includes temperature-dependent differences in liquid condensate fraction and microphysical removal rates but does not include the coupling between varying particle sizes and radiation. Investigation of cloud ice effective radii in the Thompson and Morrison scheme simulations (not shown) reveals large differences between the two schemes but only weak sensitivity to $T_{2}(0)$ in each. Lack of temperature dependence within each scheme is reassuring for our overall mechanism for suppression of Arctic air formation, but the large difference between schemes indicates that we have underestimated the spread in cooling rates that would occur for complete coupling of radiation and microphysics. Finally, we do not include in our simulations any link between aerosols and clouds or precipitation, although interactions between aerosol, cloud, and precipitation are likely important for determining cloud particle size and lifetime in the real Arctic (Mauritsen et al. 2011; Solomon et al. 2015).

\section{Conclusions}

We have used a two-dimensional cloud-resolving configuration of the WRF Model to investigate the idea that Arctic air formation is suppressed in warmer climates. Our results indicate that warming of the initial state leads to substantial inhibition of Arctic air formation via the development of optically thick low-level liquid clouds that hamper surface radiative cooling and are consistent with single-column model simulations in Cronin and Tziperman (2015). The 2-week averaged cooling decreases by roughly $0.6^{\circ} \mathrm{C}$ for each degree warming of the initial state at initial air temperatures near $0^{\circ} \mathrm{C}$, and this amplification factor rises for very warm initial air 
temperatures to as much as $1.7^{\circ} \mathrm{C}$ of reduced cooling for each degree warming of the initial state. These results are robust across several different cloud microphysics schemes, but suppression of cold-air formation is stronger in the schemes that produce the most credible mixedphase clouds and also more sensitive in these schemes to the use of a two-dimensional model rather than a singlecolumn model. Low-level clouds in the two-dimensional simulations grow more rapidly, extend to greater altitude, and persist longer as compared to analogous singlecolumn simulations, which increases the strength of the cloud feedback. The greater altitude reached and faster growth of the lower-tropospheric cloud layer appear related to cloud-top entrainment and turbulence, which is not resolved in the single-column model.

This paper has found that resolving smaller-scale processes, especially convection and turbulence at scales of $\sim 100 \mathrm{~m}-10 \mathrm{~km}$, strengthens the results of Cronin and Tziperman (2015). Many questions for future research on Arctic air formation relate to larger spatial scales and the interaction of Arctic air formation with the general circulation of the mid- and high-latitude atmosphere. How does the upward shift in cooling during the formation of cold air affect mid- and high-latitude dynamics? What pressure levels in the Arctic atmosphere are most linked to extreme cold outbreaks in midlatitudes? How robust is the low-cloud insulation mechanism to full threedimensional wind variability in a global model? What is the joint probability density function of age of terrestrial air and sea surface temperature last encountered, and how does this joint distribution change with global warming? Addressing these questions may offer new ways of understanding Arctic amplification and its coupling to changes in midlatitude extreme weather.

Acknowledgments. This work was supported by a Harvard undergraduate PRISE fellowship (HL), by a NOAA Climate and Global Change Postdoctoral Fellowship (TWC), by the Harvard University Center for the Environment (TWC), and by the NSF climate dynamics program under Grant AGS-1303604 (ET). ET thanks the Weizmann institute for its hospitality during parts of this work. We thank three anonymous reviewers for thorough and helpful comments that helped to improve the manuscript.

\section{APPENDIX}

\section{Cloud Microphysics Schemes}

We use six different microphysics schemes in this paper, denoted the Lin-Purdue, WSM6, Goddard, Thompson, Morrison, and Stony Brook schemes. Each is described in its own subsection below, emphasizing processes that produce and consume cloud ice (critical for understanding mixed-phase clouds). Most of the models are bulk schemes that use a single prognostic variable (mass mixing ratio) to model six classes of water: vapor, cloud liquid, cloud ice, rain, snow, and graupel. Exceptions to this single-moment 6-class default are noted below in the description of each scheme.

Previous work highlights the importance of liquid-ice partitioning as a function of temperature in determining the magnitude of low-cloud optical thickness feedback over the Southern Ocean in global climate models (McCoy et al. 2015). The dependence of liquid cloud condensate fraction on temperature is an informative emergent property of both the microphysics scheme and the model setup (Fig. A1) and has also been shown to be related to model biases in mixed-phase clouds (Pithan et al. 2014). As in McCoy et al. (2015), we denote the glaciation temperature for each scheme as $T_{50-50}$, or the temperature at which half of cloud water is ice and half is liquid. Curves in Fig. A1 were calculated by aggregating the liquid cloud condensate fraction for all model gridpoints with at least $10^{-4} \mathrm{~g} \mathrm{~kg}^{-1}$ of total cloud condensate among the simulations with initial surface temperatures in $\left\{-10^{\circ},-5^{\circ}, 0^{\circ}, 5^{\circ}, 10^{\circ}, 15^{\circ}, 20^{\circ}\right\} \mathrm{C}$ into bins of width $1^{\circ} \mathrm{C}$. The glaciation temperatures in our simulations are around $15^{\circ} \mathrm{C}$ higher than the near-global observations of Hu et al. (2010) and the multimodel mean in McCoy et al. (2015), and we also find a more rapid liquid-ice transition with temperature than in observations (Fig. A1). The implications of these biases are unclear; McCoy et al. (2015) suggest that higher glaciation temperature corresponds to a stronger cloud optical thickness feedback over the Southern Ocean, but clouds in our model setup often form at a much lower temperature than experienced in the lower troposphere over the Southern Ocean. We speculate that lowering the glaciation temperature of a specific scheme might lead to larger cloud optical thickness changes with warming at lower $T_{2}(0)$, perhaps shifting curves in Figs. 6 and 7 to the left.

\section{a. Lin-Purdue scheme}

The Lin-Purdue scheme is described in Lin et al. (1983) and cloud liquid and cloud ice microphysics are described in more detail in Hsie et al. (1980). Cloud ice in the model is produced primarily by supersaturation adjustment, with the fraction of supersaturation partitioned into cloud ice varying linearly from 0 at $0^{\circ} \mathrm{C}$ to 1 at $-25^{\circ} \mathrm{C}$ (e.g., at $-10^{\circ} \mathrm{C}, 40 \%$ of any vapor supersaturation in a grid cell would be converted to cloud ice, and the other $60 \%$ to cloud liquid) and supersaturation calculated as a linear mix of that over liquid and ice with the same temperature-dependent weighting. This 


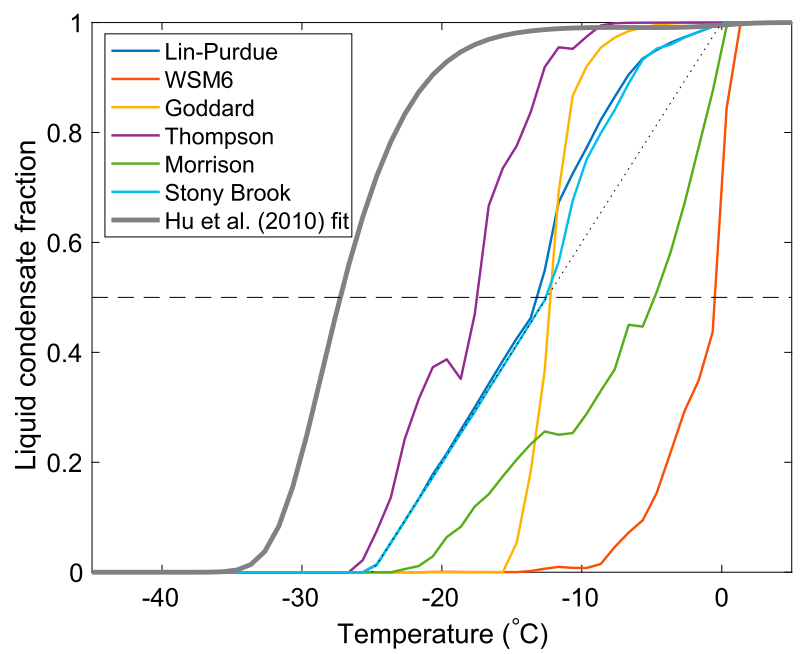

FIG. A1. Dependence of liquid condensate fraction on temperature (as in McCoy et al. 2015), taken from simulations with $T_{2}(0)$ in $\left\{-10^{\circ},-5^{\circ}, 0^{\circ}, 5^{\circ}, 10^{\circ}, 15^{\circ}, 20^{\circ}\right\} \mathrm{C}$ and averaged over all time intervals and vertical levels where total cloud condensate is greater than $10^{-4} \mathrm{~g} \mathrm{~kg}^{-1}$. The fit to global satellite observations from (1) and (2) of Hu et al. (2010) is also shown as a thick gray line.

method of supersaturation adjustment has the unrealistic consequence that all newly formed clouds below $0^{\circ} \mathrm{C}$ contain at least some ice. Offline calculations show that the production of cloud ice from cloud liquid by depositional growth-an arrow shown in Fig. 1 of Lin et al. (1983) — is entirely negligible. This simple linear ramp is responsible for the near-linear dependence of liquid condensate fraction on temperature in the LinPurdue scheme (linear ramp shown as a dotted black line in Fig. A1), with $T_{50-50}=-13.2^{\circ} \mathrm{C}$ just below the midpoint of the mixed-phase range. Liquid condensate fraction lies above this dotted line in Fig. A1 for temperatures between about $-10^{\circ}$ and $0^{\circ} \mathrm{C}$ because the model implementation of the Bergeron process leads to more rapid removal of cloud ice than it does of cloud liquid, often leading to supercooled liquid clouds that have snowed out all of their ice.

\section{b. WSM6 scheme}

The WSM6 scheme is described in Hong and Lim (2006), but many essential details of the cloud ice scheme are presented in Hong et al. (2004). Cloud ice is produced rapidly by transfer from the vapor phase, both onto existing particles and forming new particles, even at temperatures just below freezing. If little existing ice present, then the scheme produces ice by initiation of new particles, at a rate sufficient to deplete the supersaturation over ice in $\$ 1500$ s at all temperatures below freezing. If existing cloud ice is present, then vapor deposition onto existing ice particles can be a faster process, especially at temperatures slightly below freezing.
This aggressive formation of cloud ice from vapor is responsible for the extremely high glaciation temperature $T_{50-50}=-0.5^{\circ} \mathrm{C}$ in the WSM6 scheme. WSM6 also maintains clouds with the largest ice path, in part because autoconversion of cloud ice to snow has a high threshold of $0.08 / \rho \mathrm{g} \mathrm{kg}^{-1}$, but also because the parameterization of the Bergeron process does not directly transfer mass from cloud ice to snow.

\section{c. Goddard scheme}

The Goddard scheme is described in Tao et al. (1989) and Tao et al. (2003). Cloud ice production occurs by a combination of direct deposition from vapor and by the parameterization of the Bergeron process, which transfers mass directly from cloud liquid to ice and has an increase in its rate coefficient by a factor of $\sim 500$ as temperatures drop from $-8^{\circ}$ to $-15^{\circ} \mathrm{C}$. This rapid increase in conversion rate from cloud liquid to cloud ice with cooling is likely responsible for the value of the glaciation temperature $T_{50-50}=-12.2^{\circ} \mathrm{C}$, as well as the sharpness of the transition from liquid to ice clouds in the Goddard scheme (Fig. A1). The Goddard scheme has an even larger autoconversion threshold than the WSM6 scheme for forming snow from cloud ice $\left(0.6 \mathrm{~g} \mathrm{~kg}^{-1}\right)$, but it also has rapid transfer of mass from cloud ice to snow through the Bergeron process; the competition of these processes leads to it being the scheme with the second-largest cloud ice path.

\section{d. Thompson scheme}

The Thompson scheme is described in Thompson et al. (2008) and simulates two-moment rain and cloud ice (i.e., it tracks both number and mass mixing ratio variables for cloud ice and rain). The Thompson scheme also has the lowest glaciation temperature of $T_{50-50}=-17.5^{\circ} \mathrm{C}$, which is related both to its maintenance of supercooled water and its very low cloud ice mixing ratios. Two-moment cloud ice makes it far more difficult to disentangle the dominant sources and sinks of cloud ice by offline coding of process rates. Simulated cloud ice production includes heterogeneous nucleation of new ice particles at ice supersaturation greater than $25 \%$ or temperatures less than $-12^{\circ} \mathrm{C}$ and supersaturation over liquid, deposition from vapor onto existing particles, freezing of cloud liquid, freezing of small raindrops, and ice multiplication from rime splintering. The rate of cloud ice production from freezing of cloud liquid increases exponentially with supercooling and with the liquid droplet volume, following Bigg (1953).

\section{e. Morrison scheme}

The Morrison scheme is described in Morrison et al. (2009) and in more detail by Morrison and Pinto (2005), 
and it has two-moment rain, snow, graupel, and cloud ice (i.e., it tracks both number and mass mixing ratio variables for rain, snow, graupel, and cloud ice). Despite the high glaciation temperature of $T_{50-50}=-4.8^{\circ} \mathrm{C}$, the scheme is nonetheless able to produce layers of supercooled liquid cloud below $-20^{\circ} \mathrm{C}$, especially at low $T_{2}(0)$. As with the Thompson scheme, two-moment variables make it difficult to disentangle dominant sources and sinks of cloud ice. Simulated ice production includes heterogeneous nucleation of new ice particles, deposition from vapor onto existing particles, freezing of cloud liquid (similar to the Thompson scheme), accretion of cloud liquid droplets by falling ice, and distinct ice multiplication pathways from cloud liquidsnow, cloud liquid-graupel, rain-snow, and rain-graupel interactions.

\section{f. Stony Brook scheme}

The Stony Brook scheme is described in Lin and Colle (2011) and is a direct descendant of the Lin-Purdue scheme. It has a near-identical treatment of cloud liquid and ice physics, and the major difference from the LinPurdue scheme is that the prognostic graupel variable is replaced by a continuous riming intensity variable for falling ice. The liquid condensate fraction curve is almost identical to that of the Lin-Purdue scheme in Fig. A1, with $T_{50-50}=-12.6^{\circ} \mathrm{C}$.

\section{REFERENCES}

Abbot, D. S., M. Huber, G. Bosquet, and C. Walker, 2009: High$\mathrm{CO}_{2}$ cloud radiative forcing feedback over both land and ocean in a global climate model. Geophys. Res. Lett., 36, L05702, doi:10.1029/2008GL036703.

Alexeev, V. A., and C. H. Jackson, 2013: Polar amplification: Is atmospheric heat transport important? Climate Dyn., 41, 533547, doi:10.1007/s00382-012-1601-z.

Bigg, E. K., 1953: The formation of atmospheric ice crystals by the freezing of droplets. Quart. J. Roy. Meteor. Soc., 79, 510-519, doi:10.1002/qj.49707934207.

Blossey, P. N., and Coauthors, 2013: Marine low cloud sensitivity to an idealized climate change: The CGILS LES intercomparison. J. Adv. Model. Earth Syst., 5, 234-258, doi:10.1002/jame.20025.

Brient, F., and S. Bony, 2013: Interpretation of the positive lowcloud feedback predicted by a climate model under global warming. Climate Dyn., 40, 2415-2431, doi:10.1007/ s00382-011-1279-7.

Chylek, P., C. K. Folland, G. Lesins, M. K. Dubey, and M. Wang, 2009: Arctic air temperature change amplification and the Atlantic multidecadal oscillation. Geophys. Res. Lett., 36, L14801, doi:10.1029/2009GL038777.

Cronin, T. W., and K. A. Emanuel, 2013: The climate time scale in the approach to radiative-convective equilibrium. $J . A d v$. Model. Earth Syst., 5, 843-849, doi:10.1002/jame.20049.

— formation and amplify high-latitude continental winter warming. Proc. Natl. Acad. Sci. USA, 112, 11490-11495, doi:10.1073/pnas.1510937112.

Curry, J., 1983: On the formation of continental polar air. J. Atmos. Sci., 40, 2278-2292, doi:10.1175/1520-0469(1983)040<2278: OTFOCP $>2.0 . \mathrm{CO} ; 2$.

- W. B. Rossow, D. Randall, and J. L. Schramm, 1996: Overview of Arctic cloud and radiation characteristics. J. Climate, 9, 1731-1764, doi:10.1175/1520-0442(1996)009<1731: OOACAR $>2.0 . \mathrm{CO} ; 2$.

Emanuel, K., 2008: Back to Norway: An essay. Meteor. Monogr., 33, 87-96, doi:10.1175/0065-9401-33.55.87.

Greenwood, D. R., and S. L. Wing, 1995: Eocene continental climates and latitudinal temperature gradients. Geology, 23, 1044-1048, doi:10.1130/0091-7613(1995)023<1044: ECCALT>2.3.CO;2.

Hartmann, D. L., and Coauthors, 2013: Observations: Atmosphere and surface. Climate Change 2013: The Physical Science Basis, T. F. Stocker et al., Eds., Cambridge University Press, 159186. [Available online at http://www.climatechange2013.org/ images/report/WG1AR5_Chapter02_FINAL.pdf.]

Holland, M., and C. Bitz, 2003: Polar amplification of climate change in coupled models. Climate Dyn., 21, 221-232, doi:10.1007/s00382-003-0332-6.

Hong, S.-Y., and J.-O. Lim, 2006: The WRF single-moment 6-class microphysics scheme (WSM6). J. Korean Meteor. Soc., 42, 129-151. , J. Dudhia, and S.-H. Chen, 2004: A revised approach to ice microphysical processes for the bulk parameterization of clouds and precipitation. Mon. Wea. Rev., 132, 103-120, doi:10.1175/1520-0493(2004)132<0103:ARATIM>2.0.CO;2.

_, Y. Noh, and J. Dudhia, 2006: A new vertical diffusion package with explicit treatment of entrainment processes. Mon. Wea. Rev., 134, 2318-2341, doi:10.1175/MWR3199.1.

Hsie, E.-Y., R. D. Farley, and H. O. Orville, 1980: Numerical simulation of ice-phase convective cloud seeding. J. Appl. Meteor., 19, 950-977, doi:10.1175/1520-0450(1980)019<0950: NSOIPC $>2.0 . \mathrm{CO} ; 2$.

Hu, Y., S. Rodier, K.-M. Xu, W. Sun, J. Huang, B. Lin, P. Zhai, and D. Josset, 2010: Occurrence, liquid water content, and fraction of supercooled water clouds from combined CALIOP/IIR/ MODIS measurements. J. Geophys. Res., 115, D00H34, doi:10.1029/2009JD012384.

Iacono, M., J. S. Delamere, E. J. Mlawer, M. W. Shephard, S. A. Clough, and W. D. Collins, 2008: Radiative forcing by longlived greenhouse gases: Calculations with the AER radiative transfer models. J. Geophys. Res., 113, D13103, doi:10.1029/ 2008JD009944.

Kapsch, M.-L., R. Graversen, and M. Tjernstrom, 2013: Springtime atmospheric energy transport and the control of Arctic summer sea-ice extent. Nat. Climate Change, 3, 744-748, doi:10.1038/nclimate1884.

Lin, Y., and B. A. Colle, 2011: A new bulk microphysical scheme that includes riming and temperature-dependent ice characteristics. Mon. Wea. Rev., 139, 1013-1035, doi:10.1175/ 2010MWR3293.1.

Lin, Y.-L., R. Farley, and H. Orville, 1983: Bulk parameterization of the snow field in a cloud model. J. Climate Appl. Meteor., 22, 1065-1092, doi:10.1175/1520-0450(1983)022<1065: BPOTSF $>2.0 . \mathrm{CO} ; 2$.

Mauritsen, T., and Coauthors, 2011: An Arctic CCN-limited cloudaerosol regime. Atmos. Chem. Phys., 11, 165-173, doi:10.5194/ acp-11-165-2011.

McCoy, D. T., D. L. Hartmann, M. D. Zelinka, P. Ceppi, and D. P. Grosvenor, 2015: Mixed-phase cloud physics and Southern 
Ocean cloud feedback in climate models. J. Geophys. Res. Atmos., 120, 9539-9554, doi:10.1002/2015JD023603.

Morrison, H., and J. O. Pinto, 2005: Mesoscale modeling of springtime Arctic mixed-phase stratiform clouds using a new two-moment bulk microphysics scheme. J. Atmos. Sci., 62, 3683-3704, doi:10.1175/JAS3564.1.

, G. Thompson, and V. Tatarskii, 2009: Impact of cloud microphysics on the development of trailing stratiform precipitation in a simulated squall line: Comparison of one- and two-moment schemes. Mon. Wea. Rev., 137, 991-1007, doi:10.1175/2008MWR2556.1.

—_, G. de Boer, G. Feingold, J. Harrington, M. Shupe, and K. Sulia, 2012: Resilience of persistent Arctic mixed-phase clouds. Nat. Geosci., 5, 11-17, doi:10.1038/ngeo1332.

Mortin, J., G. Svensson, R. Graversen, M.-L. Kapsch, J. C. Stroeve, and L. N. Boisvert, 2016: Melt onset over Arctic sea ice controlled by atmospheric moisture transport. Geophys. Res. Lett., 43, 6636-6642, doi:10.1002/2016GL069330.

Ovchinnikov, M., and Coauthors, 2014: Intercomparison of largeeddy simulations of Arctic mixed-phase clouds: Importance of ice size distribution assumptions. J. Adv. Model. Earth Syst., 6, 223-248, doi:10.1002/2013MS000282.

Overland, J. E., and P. S. Guest, 1991: The Arctic snow and air temperature budget over sea ice during winter. J. Geophys. Res., 96, 4651-4662, doi:10.1029/90JC02264.

Peixoto, J. P., and A. H. Oort, 1992: Physics of Climate. SpringerVerlag, $520 \mathrm{pp}$.

Pithan, F., and T. Mauritsen, 2014: Arctic amplification dominated by temperature feedbacks in contemporary climate models. Nat. Geosci., 7, 181-184, doi:10.1038/ngeo2071.

— B. Bedeiros, and T. Mauritsen, 2014: Mixed-phase clouds cause climate model biases in Arctic wintertime temperature inversions. Climate Dyn., 43, 289-303, doi:10.1007/ s00382-013-1964-9.

__ , and Coauthors, 2016: Select strengths and biases of models representing the Arctic winter boundary layer over sea ice: The Larcform 1 single column model intercomparison. J. Adv. Model. Earth Syst., 8, 1345-1357, doi:10.1002/ 2016MS000630.

Sedlar, J., and Coauthors, 2011: A transitioning Arctic surface energy budget: The impacts of solar zenith angle, surface albedo, and cloud radiative forcing. Climate Dyn., 37, 1643-1660, doi:10.1007/s00382-010-0937-5.

Solomon, A., G. Feingold, and M. D. Shupe, 2015: The role of ice nuclei recycling in the maintenance of cloud ice in Arctic mixed-phase stratocumulus. Atmos. Chem. Phys., 15, $10631-$ 10 643, doi:10.5194/acp-15-10631-2015.

Stramler, K., A. D. D. Genio, and W. B. Rossow, 2011: Synoptically driven Arctic winter states. J. Climate, 24, 1747-1762, doi:10.1175/2010JCLI3817.1.

Tao, W.-K., J. Simpson, and M. McCumber, 1989: An ice-water saturation adjustment. Mon. Wea. Rev., 117, 231-235, doi:10.1175/1520-0493(1989)117<0231:AIWSA>2.0.CO;2.

— , and Coauthors, 2003: Microphysics, radiation, and surface processes in the Goddard Cumulus Ensemble (GCE) model. Meteor. Atmos. Phys., 82, 97-137, doi:10.1007/s00703-001-0594-7.

Thompson, G., P. Fiels, R. Rasmussen, and W. Hall, 2008: Explicit forecasts of winter precipitation using an improved bulk microphysics scheme. Part II: Implementation of a new snow parameterization. Mon. Wea. Rev., 136, 5095-5115, doi:10.1175/ 2008MWR2387.1.

Tjernstrom, M., and Coauthors, 2015: Warm-air advection, air mass transformation, and fog causes rapid ice melt. Geophys. Res. Lett., 42, 5594-5602, doi:10.1002/2015GL064373.

Van Tricht, K., and Coauthors, 2016: Clouds enhance Greenland ice sheet meltwater runoff. Nat. Commun., 7, 10266 , doi:10.1038/ncomms10266.

Verlinde, J., M. P. Rambukkange, E. E. Clothiaux, G. M. McFarquhar, and E. W. Eloranta, 2013: Arctic multilayered, mixed-phase cloud processes revealed in millimeter-wave cloud radar Doppler spectra. J. Geophys. Res. Atmos., 118, 13 199-13 213, doi:10.1002/2013JD020183.

Wexler, H., 1936: Cooling in the lower atmosphere and the structure of polar continental air. Mon. Wea. Rev., 64, 122-136, doi:10.1175/1520-0493(1936)64<122:CITLAA > 2.0.CO;2.

Woods, C., and R. Caballero, 2016: The role of moist intrusions in winter Arctic warming and sea ice decline. J. Climate, 29, 4473-4485, doi:10.1175/JCLI-D-15-0773.1.

Zuidema, P., and R. Joyce, 2008: Water vapor, cloud liquid water paths, and rain rates over northern high latitude open seas. J. Geophys. Res., 113, D05205, doi:10.1029/ 2007JD009040. 